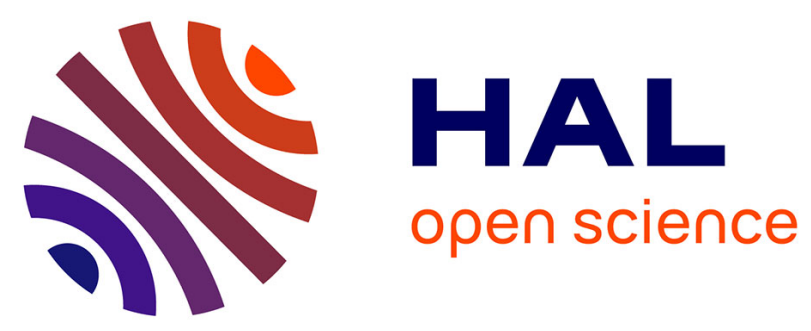

\title{
Spherical instrumented indentation as a tool to characterize porous bioceramics and their resorption
}

\author{
S. Meille, M. Gallo, P. Clément, S. Tadier, J. Chevalier
}

\section{To cite this version:}

S. Meille, M. Gallo, P. Clément, S. Tadier, J. Chevalier. Spherical instrumented indentation as a tool to characterize porous bioceramics and their resorption. Journal of the European Ceramic Society, 2019, 39 (15), pp.4459-4472. 10.1016/j.jeurceramsoc.2019.06.040 . hal-02405413

\section{HAL Id: hal-02405413 \\ https://hal.science/hal-02405413}

Submitted on 20 Dec 2021

HAL is a multi-disciplinary open access archive for the deposit and dissemination of scientific research documents, whether they are published or not. The documents may come from teaching and research institutions in France or abroad, or from public or private research centers.
L'archive ouverte pluridisciplinaire HAL, est destinée au dépôt et à la diffusion de documents scientifiques de niveau recherche, publiés ou non, émanant des établissements d'enseignement et de recherche français ou étrangers, des laboratoires publics ou privés.

\section{다)(1) $(5$}

Distributed under a Creative Commons Attribution - NonCommerciall 4.0 International 


\title{
Spherical instrumented indentation as a tool to characterize porous bioceramics and their resorption
}

\author{
S. Meille ${ }^{1}$, M. Gallo ${ }^{1}$, P. Clément ${ }^{1}$, S. Tadier ${ }^{1}$, J. Chevalier ${ }^{1}$ \\ ${ }^{1}$ Univ Lyon, INSA-Lyon, MATEIS UMR CNRS 5510, 7 avenue Jean Capelle, F-69621 Villeurbanne Cedex, \\ France
}

\section{Keywords:}

Instrumented indentation; Porous ceramics; Mechanical properties; Resorption; Bone.

\section{Abstract}

Resorbable ceramics used as porous bone substitutes are designed to favor bone in-growth and to be gradually replaced by natural tissues after in vivo resorption. However, a lack of experimental techniques to quantitatively monitor the evolution of their mechanical properties during resorption is noted. In this paper, we propose to use spherical instrumented indentation to follow-up the resorption of microporous resorbable ceramics at a local scale. Tests were performed the core and at the surface of samples immersed for different durations in model fluids. Instrumented indentation was found to be an efficient technique to characterize and to follow-up the resorption of microporous ceramics, in excellent agreement with microstructural changes observed with X-ray diffraction and Xray tomography. Instrumented indentation has the ability to capture the presence of gradients in the samples, enables the direct testing of wet samples and appears as a superior technique to compression tests mostly used in the literature.

\section{Introduction}

Resorbable ceramics are increasingly used as synthetic bone substitutes, avoiding in some clinical circumstances the need for autografts. They are usually micro- and/or macro-porous, showing an interconnected porosity favoring dissolution in physiological fluids, vascularisation, cell attachment and bone growth [1]-[3]. They also show good cyto-compatibility, the ability to resorb once implanted, and to be gradually replaced by natural bone with time. Their resorption is supposed to be mediated by chemical dissolution and by cellular activity, depending on the nature of the ceramic [4], [5].

The first resorbable ceramic was gypsum or calcium sulfate dihydrate, already used in 1892 for bone filling application. It is processed at room temperature by a hydraulic reaction. Calcium phosphates, the most common family of resorbable ceramics, were first implanted in 1920 with $\beta$-TriCalcium 
Phosphate ( $\beta$-TCP) [6]. They are processed either through a hydraulic reaction at room temperature in the form of cements, or by a thermal treatment at high temperature, as sintered ceramics. In the last decades, many studies have been carried out both in vitro and in vivo dealing with the resorption of calcium phosphates[4], [6]. The main characterization techniques used principally focus on physicochemistry and microstructural aspects (X-ray diffraction, spectroscopy, microscopies) as well as cells activity (in vitro and in vivo cellular tests).

It appears that only few studies focus on the evolution of mechanical properties during resorption [7]. However, the knowledge of the mechanical properties is critical: the material must exhibit an initial strength sufficient to avoid failure or a too rapid resorption and the release of particles that could generate inflammation in the body. On the other side, a too high stiffness should be avoided, since it is supposed to generate stress shielding. A standard target for the properties of bone substitutes is therefore that of the natural bone. The measurement of the evolution of mechanical properties versus time is also an important subject of research as the kinetics of dissolution and of bone growth will play an important role in the success of bone graft. Indeed, resorption should be neither too rapid for the new bone to grow, nor too slow to avoid formation of soft tissue around the implant.

In the few studies focused on the in vitro evolution of mechanical properties, the strength of cylindrical samples were generally tested with no real consensus or clear tendency on its evolution with time [8][10]. The measurements were conducted using uniaxial compression tests, leading to a single value of strength for each sample. However, it is well known [9], [11] that the dissolution of samples starts at the surface and, therefore, that gradients in properties appear during resorption. In the case of uniaxial compression tests, it is likely that these gradients would not be taken into account in the calculation of strength.

Indentation tests overcome this limitation by enabling a local characterization of the mechanical properties, making it possible to assess gradients of properties. Instrumented indentation with sharp tips, such as Vickers or Berkovich tips, is one of the most popular techniques for local characterization in material science, enabling for example the characterization of properties of single phases in composites or gradients in materials. Two parameters can be relatively easily extracted from instrumented indentation tests: hardness, $H$, and Young's modulus, $E$, representative of the plastic and the elastic properties of a material, respectively. The knowledge of the indenter area function (i.e., the projected contact area versus the penetration depth) as well as the contact point between the tip and the sample surface are used for the analysis of any indentation test. Several reference papers detail the different methodologies to determine $E$ and $H$ from indentation curves [12]-[14]; for further information, readers should refer to these studies as this goes beyond the scope of this paper.

Among the different indentation geometries, the use of a spherical tip further ensures a large tested volume and reduces the risks of crack initiation and propagation during the test in comparison with 
sharp tips. Indentation induced-cracks are widely used to have an estimation of the fracture toughness of materials [15] but this leads to localization of deformation that prevents the assessment of an average contribution of different phases in a material. Instrumented spherical indentation was successfully used to estimate the average $E$ and $H$ values of biological tissues (enamel [16], osteons in bone tissue [17], [18], in vivo testing of bone [19]) and of various microporous ceramics [9], [20]-[26]. Another intrinsic characteristic of spherical tips as compared to sharper indenters is their relatively smoother stress fields and larger elastic segments. This can be used to estimate a contact stress-strain relationship [27]-[29] by varying the applied load on the sample or by using spheres with different radii. The contact stress-strain curve is the plot of the mean pressure $H$ (ratio of the applied load, $P$, to the projected contact area $\pi \cdot a^{2}$, $a$ being the contact radius) versus $a / R$, the ratio of the contact radius $a$ to the sphere radius $R$. For dense ceramics, a linear part is first observed corresponding to an elastic contact, as described by Hertz's theory. Then, at increasing strain, a softening of the contact stressstrain curve is noted, related to the onset of damage and/or plasticity. For dense ceramics, plastic deformation as well as microcracking has been observed [29]. In highly porous ceramics (above $30 \%$ of pores), the main phenomenon is densification of the material induced by local grain sliding [24], [25], [30], [31]. For such materials, the elastic domain of the stress-strain curve is not always noted due to early densification.

In addition to the characterization of $E, H$, and contact stress-strain curves, the material constitutive law can theoretically be identified from spherical indentation tests coupled with finite elements (FE) simulations [32]. This is made possible by matching the experimental and model load-displacement curves through an inverse identification protocol. The unicity of the identification is theoretically possible with spherical tests due to the non-geometric similarity of this tip. However, it is practically impossible to ensure the unicity of the solution [33]. One needs to consider additional experimental features to the load-displacement curve, such as the profile of the residual imprint or densification maps [25], [34], to identify properly a constitutive law.

Due to the potential interest of spherical instrumented indentation, this paper focuses on its applicability on five different micro-porous resorbable ceramics, processed either by setting reaction (calcium phosphate cements, gypsum) or by sintering (microporous $\beta$-TCP). It gathers results from two Ph.D. works [35], [36], one dedicated to calcium sulfate and multiphasic calcium phosphate cements, the other one to monophasic calcium phosphate cements and sintered calcium phosphates. Our objective is first to assess the method to study the properties of resorbable microporous ceramics before resorption. Then, a follow-up of the evolution of mechanical properties during in vitro evolution in model solutions is presented, in parallel with physical and microstructural evolution of the materials. It includes the characterization of gradients in the materials due to the different evolutions in the core 
or at the surface. Our choice was to characterize micro-porous bioceramics. It was led by the fact that most of the current calcium phosphate cements are only micro-porous. In the case of sintered ceramics, this study aims at giving tools to investigate the properties of the micro-porous solid located between the macro-pores, averaging the contribution of both the solid phase and the micro-porosity. Further application to sintered bioceramics exhibiting both micro- and macro-porosity is finally discussed.

\section{Materials and methods}

The materials tested were resorbable microporous ceramics in the shape of cylinders (approx. $10 \mathrm{~mm}$ in height and $10 \mathrm{~mm}$ in diameter) fabricated either by a setting reaction at room temperature or by partial sintering, as detailed hereafter.

\subsection{Setting materials}

- Brushite cements were made of DiCalcium Phosphate Dihydrate (DCPD, $\mathrm{CaHPO}_{4} \cdot 2 \mathrm{H}_{2} \mathrm{O}$ ). DCPD samples were obtained via a setting reaction from $\beta$-TriCalcium Phosphate ( $\beta$-TCP) and MonoCalcium Phosphate Monohydrate (MCPM) in water [37]. The cement was injected into cylindrical molds placed vertically on a plastic film and stored at $100 \%$ of relative humidity for $24 \mathrm{~h}$. After demolding, samples were immersed in distilled water for 30 minutes and finally dried at $37^{\circ} \mathrm{C}$ until constant weight was reached.

The powder to liquid ratio (where the powder is the total weight of MCPM plus $\beta$-TCP) was equal to $0.95 \mathrm{~g} / \mathrm{mL}$, so that the final porosity of the specimens was around $60 \%$ [9].

- DiCalcium Phosphate Anhydrous (DCPA, $\mathrm{CaHPO}_{4}$ ) is also known as monetite. DCPA samples were obtained via setting reaction in the very same conditions as DCPD specimens. Once dried, however, samples were not used immediately, but rather stored for three months at ambient temperature and humidity. Final samples displayed a porosity of $75 \%$.

- Multiphasic calcium phosphate (multiphasic CaP) cement samples, consisting of a mixture of DCPD and of DCPA, were prepared by mixing $\beta$-TCP powder (purity above $96 \%$ ) with phosphoric acid in water. The powder to liquid ratio used was $1 \mathrm{~g} / \mathrm{mL}$ and the acid concentration was set to $2.2 \mathrm{M}$. Samples were stored at $37^{\circ} \mathrm{C}$ and $100 \%$ of relative humidity for 2 days and then dried at $37^{\circ} \mathrm{C}$ until constant mass. The final composition was of $22 \mathrm{wt} . \%$ DCPD, $59 \mathrm{wt} . \%$ DCPA, $15 \mathrm{wt} . \% \beta$-TCP and $4 \%$ hydroxyapatite (HA) as determined by Rietveld analysis. The residual micro-porosity was of $66 \%$.

- Gypsum samples were processed by a setting reaction of calcium sulfate hemihydrate powder and water to form calcium sulfate dihydrate $\left(\mathrm{CaSO}_{4} \cdot 2 \mathrm{H}_{2} \mathrm{O}\right)$. The water to plaster mass ratio used was 0.8 , samples were stored at room temperature and $100 \%$ relative humidity for 1 day to ensure 
total hydration, leading to a sample porosity of approximately $56 \%$ after drying. Additional details can be found in [24].

\subsection{Sintered material}

- Microporous $\beta$-TCP samples were kindly provided by Prof. Marc Bohner (RMS Foundation, Switzerland). Briefly, a Ca-deficient apatite cement obtained by mixing $\alpha$-TCP powder with an emulsifying solution and paraffin oil was injected into cylindrical molds $(9.5 \times 9.5 \mathrm{~mm})$ and incubated at $60^{\circ} \mathrm{C}$ and $100 \%$ humidity for $72 \mathrm{~h}$. After demolding and soaking into Petroleum ether to remove as much paraffin as possible, samples were sintered at $800^{\circ} \mathrm{C}$ to convert the Ca-deficient apatite phase into $\beta$-TCP [36]. The average porosity of final specimens was equal to $79 \%$.

\subsection{Surface Preparation}

Samples processed by setting reaction showed flat upper and lower surfaces after casting of the slurry in cylindrical molds placed on a polymer film. Instead, sintered samples ( $\beta$-TCP) were cut at low speed with a diamond saw and manually polished, without water or lubricants, using diamond lapping films (down to $0.1 \mu \mathrm{m}$ grain size), so to obtain two parallel and flat surfaces needed for indentation of the samples surface. Surface preparation of the samples was only made before immersion. When analyses of the inner part of the specimens (hereafter called "core") were required, samples were simply cut with a low-speed saw, but not polished. Obtaining a flat surface by polishing a porous brittle material turns out to be much more difficult as compared to dense materials. Improvements in samples preparation are possible, for example by impregnating the material with paraffin during the polishing stage and by afterwards eliminating the organic phase with a thermal treatment. However, this approach is limited to temperature resistant materials (and cannot be applied to DCPD, DCPA, gypsum, and multiphasic CaP samples).

\subsection{Indentation test}

Indentation tests were performed using two devices. Gypsum and DCPD cements were tested with an Electroforce 3200 machine (BOSE, USA), using a $1 \mathrm{~mm}$ diameter tungsten carbide sphere and at a load controlled speed of $0.3 \mathrm{~N} . \mathrm{s}^{-1}$. A capacitive displacement sensor with a resolution of $0.05 \mu \mathrm{m}$ and a $200 \mathrm{~N}$ load cell were used. $\beta$-TCP samples were tested with a nanoindenter G200 (Agilient, USA), with a $2 \mathrm{~mm}$ diameter alumina sphere. A controlled strain rate $\left(0.03 \mathrm{~s}^{-1}\right.$ as calculated from [38]) was used. All tests were performed at $22^{\circ} \mathrm{C}$ in a relative humidity between $30 \%$ and $50 \%$. Tests were analyzed using the Oliver \& Pharr method [39] to extract hardness and Young's modulus from the unloading curve, as no piling up around the residual indents was noted [24]. A schematic representation of the contact zone is shown in Figure 1a. Tests carried out with the nanoindenter were also analyzed with 
continuous stiffness measurement mode (CSM) with a $2 \mathrm{~nm}$ displacement amplitude at a frequency of $45 \mathrm{~Hz}$, allowing the continuous measurement of Young's modulus and hardness versus the penetration depth during the test.

The choice of the device is mainly governed by the displacement range, limited to approximately $50 \mu \mathrm{m}$ for the nanoindenter and up to $1 \mathrm{~mm}$ for the Electroforce machine. The choice of the sphere size and of the maximal penetration depth was made to avoid the influence of surface roughness and to ensure an average contribution of solid and porous phase in the tested zone, as explained in Clement et al. [24] and in Staub et al. [25] and as detailed in the next section.

The minimum center-to-center distance between two neighbor indents was equal to four times the indentation radius to avoid any interaction between one indentation and the adjacent one. This experimentally validated criterion was based on the fact that densification occurs with a hemispherical shape below the indenter for porous ceramics with a limited lateral expansion [24], [40], in contrast with the indentation of ductile metals, showing extensive pile up around the indent.

Calibration of the system frame and of the area function of the spherical tip was made using reference materials with well-known elastic moduli (pyrocarbon, fused silica, and tungsten). The contact point was corrected implementing the method proposed by Moseson et al. [26], [41], [42]. For each test condition in the in vitro resorption tests, three specimens were tested at the surface (8 indentations per sample) and two at the core (8 indentations per sample).

As the method developed in this work to monitor the evolution of mechanical properties should be able to follow-up very different phenomena and kinetics, several materials and immersion conditions were tested. In vitro dissolution tests were performed for all calcium phosphate materials (only gypsum samples were not tested, because of their too rapid dissolution process). Briefly, samples were immersed either in $0.1 \mathrm{M}$ tris(hydroxymethyl)aminomethane (TRIS) or in Phosphate Buffered Saline (PBS) solutions, buffered at $\mathrm{pH} 7.4$ and maintained at $37^{\circ} \mathrm{C}$. In some cases, the immersion solution was periodically refreshed (either on a daily basis or each time the $\mathrm{pH}$ deviated from 7.4). In some other cases, the samples remained in the same solution all along the experiment. More details about these dissolutions tests can be found elsewhere [7].

\subsection{FE Modeling}

FE modeling was used to identify a constitutive law for the material through an inverse identification procedure. The choice of the constitutive law is discussed in the following section.

The numerical analysis of spherical indentation tests was carried out using ANSYS $^{\circledast}$ finite element commercial package. Owing to the system symmetry, the analysis was performed with a 2D axisymmetric model using 8-node biquadratic elements. The mesh was refined towards the contact zone with an element size of $3 \mu \mathrm{m}$. The total number of elements was over 3000 . The boundary 
condition for the base was considered as frictionless, preliminary calculation having shown that the influence of friction on the base was negligible. The vertical displacement of the interior surface of the sample was blocked and the experimental displacement was applied to the indenter via the reference node of the rigid sphere.

The elastic behavior was entirely described by the two parameters $E$ and $v$, respectively Young's modulus and Poisson's ratio of the material. $E$ was set to the experimental value measured with spherical indentation tests. $v$ was set to a value obtained for highly porous materials, independently of the Poisson's ratio of the solid matrix, and equal to 0.22 [43], [44].

The elasto-plastic material used in the finite element analysis was assumed to follow a Drücker-Prager cap model, which is an association of a Drücker-Prager (DP) criterion and a cap at high pressures.

The yield function $F$ is given by:

$$
F(\tilde{\sigma})=\sqrt{J_{2}(\tilde{\sigma})}+\alpha I_{l}-k=0
$$

with $I_{1}$ the first invariant of the stress tensor, $J_{2}$ the second invariant of the deviatoric stress tensor, $k$ the cohesion and $\alpha$ the friction parameter. $\alpha$ should be smaller than $\sqrt{3} / 2$, the upper limit value for which the use of a DP criterion is considered as valid [45], [46]. A non-associated flow rule was chosen, described by the following equation: $G(\tilde{\sigma})=\sqrt{J_{2}(\tilde{\sigma})}+\beta I_{l}$ with $\beta$ the dilatancy parameter.

The material parameters were identified via an inverse method. This method consisted in simulating the indentation test and adapting the materials parameters in order to minimize the difference between the numerical simulation and the corresponding experimental results. This minimization was made in the least squares sense. The resolution of this optimization problem was implemented in MIC2M software using a Levenberg-Marquardt algorithm (see details in the method in [25], [47], [48]).

\section{Results and discussion}

\subsection{Reference materials before resorption}

\section{Spherical indentation test}

Figure $1 \mathrm{~b}$ shows a typical experimental load-displacement curve with one loading-unloading cycle on the surface of a microporous sintered $\beta$-TCP sample. The oscillations noted in the loading curve are attributed to repeated events of porosity collapse and local densification, as already noted on porous rocks [49] and gypsum plaster [24], [40]. An irreversible penetration of the tip was noted after unloading, corresponding to a residual imprint on the sample surface (as illustrated in figure 1a). Profilometry measurements showed the absence of piling-up around the residual indent and the good agreement between the experimental value of the radii of contact and the calculated value based on Oliver and Pharr method. 
Using the CSM mode, the evolution of $E$ and $H$ can be plotted versus the penetration depth. After a sufficient penetration depth, estimated at $0.8 \mu \mathrm{m}$ in Figure $1 b, E$ is nearly constant (Figure 1c), whereas $H$ increases with penetration depth (Figure 1d), a common feature for spherical indentation as explained hereafter. Experimental values of $E$ and $H$ for small penetration depth were highly dispersed and should not be taken into account as the contact surface between the tip and the sample was influenced by the surface roughness of the sample. To avoid the influence of surface roughness, the minimal penetration depth was found to be at least five times the root mean square (RMS) roughness, as already noted for indentation tests on cement pastes [50]. Typical values of RMS roughness for porous resorbable ceramics lie between $150 \mathrm{~nm}$ and $1 \mu \mathrm{m}$, the highest values being observed especially for calcium phosphates and gypsum samples after in vitro resorption that was found to increase the samples roughness [9], [24]. The total penetration depth during all indentation tests in this work was therefore typically above $10 \mu \mathrm{m}$. Tests at different locations on a reference sample confirmed that $E$ and $H$ were consistent and that the test conditions enabled the characterization of a representative elementary volume of the material, including the contributions of both solid and porous phases.

The indents' radius of contact, $a$, can be derived from the penetration depth through the following equation obtained by simple geometrical considerations (see Figure 1a):

$$
a=\sqrt{2 R \times h_{c}-h_{c}^{2}}
$$

with $a$ contact radius, $R$ sphere radius and $h_{c}$ contact depth.

For large penetration depths (typically for $a / R$ above 0.3 to 0.5 depending on the material), the unloading curve could not be fitted by a power law, showing a too large size of the densified zone, with possible macro-crack formation during the test [24]. The hypothesis that the unloading curve was purely elastic was no more valid and the extraction of mechanical parameters from analytical models for homogeneous materials was no more possible. In addition, it has to be remembered that the maximum penetration depth should be of one tenth on the sample thickness to avoid the influence of the support underlying the sample.

To summarize the typical characteristics of the indentation tests performed in this study, the sphere size varied from 1 to $3 \mathrm{~mm}$, the maximum penetration depth varied between 10 and $100 \mu \mathrm{m}$ (maximum load depending of the materials, but typically from 0.5 to $5 \mathrm{~N}$ ) and the contact radius $a$ from 100 to $500 \mu \mathrm{m}$. This gave an $a / R$ range between 0 and 0.5 .

As already mentioned, it is possible to extract a contact stress-strain curve from the experimental loaddisplacement curve by plotting the mean applied pressure i.e., the mean pressure $H$, versus the ratio 
of the contact radius $a$ to the sphere radius $R, a / R$. Such a plot enables gathering data obtained with different penetration depths and sphere radii in a single curve. Figure 1 e shows the indentation stressstrain curve for a $\beta$-TCP sample. Two main parts are visible: a first part, at low deformation, where the pressure increased with deformation, followed by a pressure plateau for higher applied deformations (for $a / R>0.1$ ). This behavior is typical of micro-porous ceramics tested with large spheres [29]. The first part of the curve is related to the formation of a damaged zone below the indenter, followed by a compaction of this zone at nearly constant pressure. For less porous ceramics, the stress-strain curve is bi-linear with a clear initial elastic behavior and a non-constant value of pressure during compaction [29]. Theoretically, the initial part of the pressure-deformation curve is linear and can be described by the Hertz law for an elastic contact, showing a linear relationship between $H$ and $a / R$ with a slope of $\frac{4 \pi}{3} E$. Experimentally, the observation of a linear part in the contact pressure-deformation curve depends on the ability to prepare a flat surface, and, therefore, on the hardness of the material, that needs to be sufficiently high. This has been shown to be possible for porous samples with a hardness measured by spherical indentation typically above $50 \mathrm{MPa}$ [25], but practically impossible for the porous ceramics tested in this study.

For porous materials, hardness values determined with a spherical tip at the plateau of pressure are always lower than those determined with a sharp tip, i.e., Vickers or Berkovich for the most common ones [29]. This is explained by the stress singularity generated with sharp tips that favors damage at low loads and results in a stronger densification and higher hardness.

\section{Mechanisms activated during indentation}

Observation of the residual indents gives useful information on the microstructural mechanisms occurring during a spherical indentation test. Figures $2 \mathrm{a}$ and $\mathrm{b}$ present slices of a X-Ray Tomography reconstructed volume of an indented multiphasic CaP cement. Densification under the indents is clearly highlighted by brighter (thus denser) areas. Figure $2 c$ shows a cross section view of the area below a residual indent, at lower resolution. Densification by pore collapse was responsible for the residual imprint. As resorbable ceramics have commonly more than $50 \%$ of micropores, accommodation of the deformation can be explained by a densification of the volume of material under the indented surface. This feature has already been shown for porous materials (macroporous ceramics [40], [51], foams [52], coatings [26], [29], [53], catalyst supports [25], technical ceramics [54], [55], glasses [34], aerogels [56], [57]). In the case of materials with a poly-dispersed porosity, densification is shown to occur by the collapse of the larger pores (see [25], [40]).

\section{Influence of material properties}


Table 1 gathers the Young's modulus $E$ and the hardness $H$ measured on the pressure plateau (see Figure 1e), for samples tested in this study as well as for samples from literature, processed either by a setting reaction or by an incomplete sintering. It can be noted that the porosity level logically decreases the stiffness and hardness of materials. The ratio $E / H$ lies between 25 and 260 for all porous samples (see Table 1).

A large difference of $E / H$ ratios was noted between different ceramics. This ratio can be as high as $100-$ 250 for gypsum, DCPD and DCPA, whereas values between 20 and 50 are noted for $\beta$-TCP (this work), lanthanum strontium cobalt ferrite, hydroxyapatite and alumina (literature data). For dense or nearly dense materials, the difference may be related to the nature of inter-crystalline bonds. Materials with mainly ionic and covalent bonds tended to give lower $E / H$ ratios as compared to materials with weaker bonds (van der Waals, hydrogen), even if structural parameters such as grain size can affect the $E-H$ correlation, but in a narrower range [58].

For a given material, increasing porosity fraction led to a decrease of both Young's modulus and hardness. In general, the hardness seemed quantitatively more affected by this loss of properties, leading to a higher $E / H$ ratio (see table 1 for gypsum, $\beta-T C P$, alumina and LSCF). This is in good agreement with the work of Rice on porous ceramics [58]. Models to estimate $E$ for porous materials are based on an average of the volume fractions of solid and porous phases. For hardness, pores generate high stress concentrations zones that lead to micro-cracking and damage. In that case, porosities behave like weak points in the structure and have a stronger influence than on the elastic modulus.

The areas under the unloading curve and between the loading and unloading curves (see Figure 1b) are representative of the reversible and of the irreversible energy brought to the system, respectively. The ratio of irreversible energy to the total energy has been shown to be directly correlated with the $E / H$ ratio (Cheng Cheng). For highly porous ceramics with a high $E / H$ ratio, only a limited fraction of the energy was released after unloading (see Figure 1b). Most of the energy corresponded to irreversible phenomena and particularly densification, starting at relatively low pressures due to the high porosity fraction.

\section{Identification of constitutive laws}

Instrumented indentation enables the identification of a constitutive law by coupling the experimental test with a numerical model and using an inverse analysis. A critical question for the modelling lies in the choice of the constitutive law and of the yield criterion for the material.

An extensive work on the definition of yield criterion for porous minerals was made in rock mechanics [59]. Mohr-Coulomb or Drücker-Prager are well-known yield criteria showing pressure sensitivity, 
relevant for ceramic materials that exhibit a large compression strength as compared with their tension strength. The latter criterion is largely used to describe the mechanical behavior of porous rocks [60], [61] and can be coupled with a cap at high hydrostatic pressure [25], [62], [63] to capture densification phenomena.

In porous ceramics used in fuel cells with porosity ranging from 5 to $45 \%$, a specific model was developed to simulate indentation-induced densification. It is based on the Gurson model [64] initially developed for metals containing a dilute fraction of pores, typically below $10 \%$ [65]. In that case, the densification under the indenter can be effectively simulated, but the material parameters have no fundamental significance. Elliptic models were also used to model the mechanical behavior of microporous gypsum [44] and to simulate the densification of amorphous silica under indentation [34], [66].

In this study, a Drücker-Prager criterion has been chosen thanks to its large use in modeling the compression behavior of porous ceramics or rocks and to the physical meaning of its material parameters (cohesion, friction angle, dilatancy angle). A schematic representation of its limit surface in the hydrostatic stress versus deviatoric stress plane is presented in Figure 3a. This criterion is defined by two parameters: cohesion $k$ and friction angle $\alpha$ (Figure 3a). The dilatancy angle $\beta$ characterizes the behavior after the elastic domain. The first column of Table 2 shows the parameters identified for a DP model on a multiphasic calcium phosphate cement in dry conditions before in vitro evolution. The identification was carried out using an inverse approach a detailed in section 2.5. The corresponding experimental data and numerical simulations are shown in Figure $3 \mathrm{~b}$. One can note the good correspondence between the identified and the measured Young's moduli. The residual profile of the imprint was also correctly simulated and showed no piling up, as experimentally noted [24]. This can be explained by the accommodation of deformation by densification under the indent, favored by the high porosity fraction. The dilatancy angle was close to zero for porous ceramics during the tests, as frequently noted for highly porous rocks [67].

The densification of the material could be taken into account by closing the limit surface by a cap at high hydrostatic pressures (Figure 3a), as is commonly done in rocks mechanics. Additional parameters need then to be identified, such as the hydrostatic pressure limit $P b_{0}$ and the densification law (evolution of the hydrostatic pressure during densification [25]). However, increasing the number of parameters to be identified from an indentation curve decreased the precision of the fitted parameters. It was then required to run other complementary tests to determine specific parameters: for example, a hydrostatic compression test can be performed for determining $P b_{0}$ [25].

\section{Application to reference materials}


An important advantage of indentation testing is the assessment of properties at a local scale. As an example, a difference in properties has been highlighted between the core and the surface of the DCPD, DCPA, and $\beta$-TCP samples, already before resorption. In particular, for both samples, higher values of hardness were observed at the surface (see Table 3). A harder surface is related to a specific crystal orientation in the outer part of the specimens (in contact with the mold during setting) leading to a local reinforcement due to an increase of local density (see Figure 4). Instrumented indentation is therefore able to capture such surface effects.

\subsection{Follow-up of the evolution of materials during in vitro evolution}

\section{Tests on different materials}

The in vitro evolution of resorbable ceramics is known as being induced by cellular process and/or dissolution process [1], [4], [5]. This phenomenon starts from the surface of microporous samples and proceeds towards the bulk [9], generating a gradient in properties, in addition to the gradients possibly created during fabrication of the samples, such as crystalline orientation at the surface (Table 3, Figure 4). As previously mentioned, instrumented indentation is a local characterization method and enables the characterization of the properties at the surface and in the bulk (after cutting the sample into two halves) samples after in vitro evolution.

Figure 5 and Tables 4 to 6 show the evolution of Young's modulus and hardness at maximum penetration for specimens resorbed in vitro and tested by spherical indentation. As previously mentioned, the reported values concern three different calcium phosphate cements (DCPD in Figure 5a and Table 4, DCPA in Table 5, multiphasic CaP cement in Figure 5b and Table 6) and one pre-sintered ceramic ( $\beta$-TCP in Table 7). Different tendencies were noted depending on the materials tested and on the immersion conditions (nature of the fluid, liquid/solid ratio, refresh of the solution, stirring).

- DCPD cement was tested after soaking in TRIS solution with daily refresh of the solution (Figure $5 a)$. At the surface, a decrease of properties was noted with time, starting from 4 days of immersion (and for longer durations when the solution was not refreshed [9]). This decrease in properties (-50\% for $E$ and $H$ after 8 days of soaking, Table 4 ) was mainly explained by a physico-chemical dissolution of DCPD crystals, leading to a higher porosity at the surface of the sample [9]. At the core, no clear evolution of the properties could be noted up to 14 days of immersion, marking a clear difference with the behavior at the surface.

- For the case of monophasic DCPA samples stored in TRIS solution (with daily solution refresh) for 14 days, a different trend was observed with an increase of both hardness and Young's modulus (Table 5). At the surface of the samples, an increase of $180 \%$ in $E$ and $125 \%$ in $H$ was noted, whereas at the core of the sample, these increases were $35 \%$ in $E$ and $21 \%$ in $H$, respectively. This evolution was explained by the precipitation of other calcium phosphate 
phases (octacalcium phosphate (OCP) and apatite) on DCPA crystals and in microporosities (data not shown), leading to an increase in properties even if a decrease of $6 \%$ in density was noted due to a concomitant dissolution of DCPA crystals. The precipitation occurred sooner and mainly at the samples surface, while at the core small amounts of OCP were noted only after 14 days of immersion (data not shown).

- Multiphasic DCPD-DCPA cements were monitored by instrumented indentation after immersion in Phosphate Buffered Saline (PBS) with periodic solution refresh (that is, every time the $\mathrm{pH}$ dropped from 7.4 to values lower than 7.0). Evolution of Young's modulus and hardness is shown in Figure 5b. A first stage with minimal evolution was noted, followed by a rapid increase in stiffness and hardness of the samples, starting at day 1 for the surface and day 8 for the core. Final values of $E$ and $H$ were respectively two and three times higher than the initial values before immersion. As for monophasic DCPA samples, the increase in properties could be attributed to the precipitation of OCP and apatite on the network of DCPA/DCPD crystals, as shown through physical and microstructural analysis of the samples (see Figure 6 and Figure 7). On X-ray tomography volumes, a denser surface layer growing with increasing evolution time can be noticed (Figure $6 \mathrm{~b}$ ). The precipitation of small crystals onto the existing network of dissolving crystals and in the microporosities (Figure 7) strengthened the material, even though the immersion led to a decrease in density of the samples $(-12 \%$ after 28 days), related to the dissolution of DCPA/DCPD crystals. The precipitation noted at the surface was shown to locally prevent the dissolution of DCPD/DCPA crystals.

Scattering in the experimental measures increased with immersion duration, especially for surface measurements (Figure 5b); this has to be linked with the surface roughening due to dissolution and precipitation during soaking.

Core and surface tended to reach similar values for long immersion times (28 days, Figure $5 b$ ). However, a gradient in properties was noted before immersion, with slightly higher mechanical properties at the surface than at the core (Table 6). This gradient could be related to the crystal orientation, as already noted for DCPD (Figure 4): crystals with a high aspect ratio tend to orient parallel to the surface during setting reaction when they are located close enough to the outer surface. This gradient disappeared rapidly (after 30 minutes) with the dissolution of the sample, since the first crystals to dissolve were those at the surface.

- In addition to cements processed through a setting reaction, pre-sintered $\beta$-TCP samples were also characterized by instrumented indentation during in vitro evolution in TRIS solution. Evolution of $E$ and $H$ without refresh are presented in Table 7. A rapid decrease of the mechanical properties was noticed at the surface $(60 \%$ of decrease for $H$ and $15 \%$ for $E$ after one week of immersion), whereas no evolution was noted in the core until 8 weeks of 
immersion, explaining why no signs of resorption were noted on X-ray tomography volumes (data not shown). Thus, for this material, instrumented indentation resulted to be very sensitive to early modifications of the microstructure, even more than X-ray tomography. The rapid loss of hardness and Young's modulus at the surface may probably be explained by dissolution of $\beta$-TCP grain boundaries and loss of some of the unbound grains in the solution [36]. On the other hand, for samples immersed with refresh of the solution, the kinetics of dissolution was speeded up and a porous shell was noted on X-ray tomography after one week of immersion (Figure 8a).

As a conclusion, the here-presented results of indentation tests performed on several materials show that structural changes caused by in vitro resorption can lead to different evolution of mechanical properties, this being explained by different phenomena depending on the material composition and on the testing conditions [7]. This confirms the importance of monitoring at the same time physicochemical, microstructural and mechanical properties during in vitro evolution for a better understanding of the underlying mechanisms. To further illustrate the possibilities offered by indentation testing, a sintered $\beta$-TCP sample retrieved after 1 week from a daily refreshed TRIS solution was cut and then indented all along its diameter, with a distance between indents of $1 \mathrm{~mm}$. The evolution in properties along the diameter (shown in Figure 8b) showed the appearance of a gradient after 1 week only, with lower properties close to the surface. This was perfectly consistent with the microstructural changes evidenced by X-ray tomography.

\subsection{Discussion on the strengths and limitations of spherical indentation}

As illustrated in all the previous results, it appeared that Young's modulus and hardness parameters were clearly correlated in their evolution with resorption duration, whatever the materials tested and the resorption conditions. Hardness is a plastic parameter, directly related to the damaged zone under the indent. The damaged zone (illustrated in Figure 2c) was approximately hemispherical, with a typical size of twice the maximal penetration depth. Besides, this is confirmed by other studies on porous ceramics under spherical indentation [40]. Young's modulus measurement involves a larger volume of material, the whole volume submitted to elastic stresses during the test. However, modifications in hardness values were not observed earlier (i.e., for short immersion durations) than changes in Young's modulus. This may be linked to the relatively important experimental scattering, due to the nonperfectly flat samples and to the average contribution of different phases in the material.

As mentioned in section 3.1, instrumented indentation can be coupled with numerical analysis to identify a constitutive law. Inverse identification was applied on multiphasic CaP cement after 1 day and 56 days of in vitro soaking as shown in Figure $3 \mathrm{~b}$ and Table 2. The analysis was carried out 
considering a Drücker-Prager criterion without cap as detailed in [24]. Young's modulus, cohesion, and friction angle (see Figure 3a) appeared to decrease during the first day of immersion and then to increase from 1 to 56 days, all three parameters with a similar relative evolution. This was related to an initial dissolution of DCPD crystals at the surface (day 1 in Table 2) followed by a reinforcement of the material by precipitation of apatite and OCP (see Figure 7). The dilatancy angle was kept constant after soaking, close to zero, with a limited sensitivity to the response. More detailed analyses should be performed including on the densification of the material during indentation (as observed in multiphasic CaP, Figure $2 \mathrm{~b}$, and in gypsum samples, Figure $2 \mathrm{c}$ ) to confirm if the densification process was affected by the resorption.

\section{Comparison with compression test}

To evaluate the interest of instrumented indentation, it appears necessary to compare this test with a uniaxial compression test, the most popular mechanical test used in the literature during in vitro studies [68], [69]. Figure 9 shows the compression tests carried out on $\beta$-TCP samples before and after immersion for 2 weeks in TRIS solution with daily refresh. All samples were tested in a dry state, and a total of six samples per configuration were used. Before immersion, a similar value of $E$ was noted using indentation at the sample's surface or using compression test (788 MPa and $747 \mathrm{MPa}$ respectively). Logically, the maximal load in uniaxial compression showed a decrease with resorption $(-20 \%)$, because of the dissolution of the sample surface. However, for the sample immersed for 2 weeks, a calculation of the Young's modulus and an estimation of the fracture stress was not possible as the resorption was not homogeneous in the sample, as shown in Figure 8. Different slopes obtained during loading and loading/unloading cycles in compression and pictures of the sample during the test highlighted the crushing of the upper and lower surfaces (Figure 9b). The unloading curve gave a modulus of $665 \mathrm{MPa}$, similar to the reference state before immersion. This result confirmed that the core of the sample was unaffected by the immersion, as previously evidenced by indentation (Table 7). However, the loss of properties at the surface could not be obtained from a uniaxial compression test. On the contrary, a significant decrease in mechanical properties at the surface was evidenced by the spherical indentation method (Figure 9c). Finally, it is worth noting that, since several indentations can be performed on the same specimen, a single sample can lead to statistically significant results (Figure 8c).

\section{Test in humid conditions}

Resorbable ceramics and cements are used in liquid environment, and their high porosity favors the interaction with fluids. Testing materials in their service conditions brings additional value, particularly when knowing that the drying step can lead to the precipitation of new phases and generate 
experimental artifacts [9]. For comparison, indentation tests can be carried out on wet samples, just withdrawn from the immersion solution, and on the same samples after drying at $37^{\circ} \mathrm{C}$ until constant weight. Figure 10 presents tests carried out on DCPD samples, after drying or on samples kept wet, before immersion and after 14 days in TRIS solution without refresh. A clear impact of the test conditions was noted with an increased penetration depth for wet samples as compared to dry ones. Concerning the influence of in vitro evolution, a similar mechanical behavior was noted before and after immersion, confirming a limited effect of immersion in case of absence of refresh of TRIS during soaking. The increase in deformation during indentation in wet conditions can be explained by the influence of water on inter-crystalline bonds (decrease of electrostatic bonds), by viscous mechanisms related to possible crystal sliding [70], and by local dissolution. The decrease in electrostatic bonds in the presence of water has already been largely described for ionic solids processed through a hydraulic reaction, such as calcium sulfate cements [71]-[73] or calcium phosphate cements [69], [74].

\section{Further exploitation of instrumented spherical indentation}

To further improve the modelling of the test, several options have to be considered in the future:

- A better description of the densification below the indenter is necessary, using complementary tests such as instrumented hydrostatic compression to determine the evolution of the hydrostatic pressure versus densification strain [25].

- In this work, the microporous material is considered with an isotropic behavior, averaging the contributions of solid phase and microporosity. However, the presence of gradients during resorption has been clearly identified in this work and need to be modelled to get an accurate description of the mechanical behavior, as already shown for layered ceramics [26], [29]. At a longer term, taking into account the influence of spatial heterogeneities in the microstructure (for example, spatial variation in the porosity fraction in the material) on its mechanical behavior would bring additional value, especially towards the knowledge of the microstructure - properties relationship. This can be implanted in a FE model [75] or using discrete element modeling [76].

- The time-dependent properties need to be taken into account in the model, especially when tested in wet conditions. This has been already done for bone tissue [77], [78], as the hydration state of the samples can modify their properties. In bone tissue, a viscous contribution to the mechanical properties is also known to come from the organic component of the material, mainly collagen fibers [79]. Time-dependent models permit to distinguish the respective contributions of mineral and organic phases on the mechanical response of bone tissue [18], [80], [81]. Recently developed bone substitutes for tissue engineering are indeed porous composite materials, with resorbable ceramic and polymeric components, such as polycaprolactone, chitosan, or polylactic acid [82], 
[83], [84]. For these materials, the ability to distinguish the contributions of both mineral and organic phases is of major interest and can be fulfilled with instrumented indentation. Taking into account the time dependent properties in models has however the drawback of increasing the complexity of the modelling and raises questions on the validity of identified properties.

This work focused on microporous materials only. Testing macroporous bioceramics, which are often used in clinics, would be possible. A larger spherical tip with an significant penetration depth has already been successfully applied on macroporous gypsum used as a construction material [40], [51]. Another option to characterize macroporous materials is to test the microporous zone between the macropores. This was found to be an effective way of characterizing the in vivo resorption of a $\beta$-TCP bone substitute explanted from a sheep [85]. Instrumented indentation tests were carried out on polymer impregnated samples, facilitating the sample preparation and especially the polishing step, but modifying the mechanical properties. Comparison of properties between different locations on the sample are still possible and mineralized tissue growth in the micropores of the $\beta$-TCP ceramic was found to significantly increase the local rigidity and hardness (more than $100 \%$ increase) as compared to ceramic without bone growth in the pores after six months of implantation.

\section{Conclusion}

Instrumented spherical indentation is efficient to determine the average properties of microporous materials at a local scale (indents with a typical diameter of hundreds of microns). This method is particularly sensitive to small changes in the structure of samples that could not be identified by other characterization techniques. In comparison with a uniaxial compression test, instrumented indentation is well adapted to the characterization of small samples, detecting gradients of properties. This is often encountered during in vitro evolution of resorbable ceramics, since dissolution and precipitation occur first at the surface of samples. In addition, this test is rather simple to run and can be adapted to test samples in a humid state, close to the usage environment. It is therefore a high-potential technique to be coupled with structural and physico-chemical characterization for a multi-physics monitoring of the evolution of resorbable materials.

Instrumented indentation coupled with numerical simulation enables to determine a constitutive law of the material. However, the mechanical analysis of this test is rather complex due to the inhomogeneity of the stress field generated. Similarly, instrumented indentation can be used on samples after in vitro cellular tests, to check the evolution of local properties [86] and also in vivo [19] due to its quasi non-destructive character. This confirms the high interest for this technique in the field 
of biomaterials and more generally in porous ceramics, also used as construction materials, materials for SOFC, filters, catalyst supports, etc.

\section{Acknowledgements:}

Emmanuel Artiges for the compression tests, Marc Bohner (RMS foundation, Switzerland) for the supply of the $\beta$-TCP samples, Jérôme Adrien (MATEIS) for X-ray tomography, Laurent Gremillard (MATEIS) for Rietveld refinements of $\mathrm{X}$-ray diffractograms.

This work was supported by the European Commission funding of the 7th Framework Program (Marie Curie Initial Training Networks; grant number: 289958, Bioceramics for bone repair) and by the French Ministry for Education and Research, through a "Thématiques prioritaires" grant. 
Table 1: Young's modulus, $E$ and hardness, $H$, determined by instrumented indention on different porous ceramics before resorption. Data are sorted out by increasing porosity fraction for a given material. Hardness was measured on the pressure plateau of contact stress-strain curves in spherical indentation except for dense $\beta$-TCP, where the Vickers hardness was considered (no data in spherical indentation).

\begin{tabular}{|c|c|c|c|c|c|}
\hline Material & $\begin{array}{l}\text { Porosity } \\
\text { (\%) }\end{array}$ & $\begin{array}{c}E \\
\text { (GPa) }\end{array}$ & $\begin{array}{c}\mathrm{H} \\
(\mathrm{MPa})\end{array}$ & $E / H$ & Reference \\
\hline \multirow{3}{*}{ Gypsum } & 5 & 25 & 340 & 74 & [87] \\
\hline & 30 & 15 & 120 & 125 & [24] \\
\hline & 55 & 5 & 22 & 227 & \\
\hline Multiphasic CaP & 60 & 0,65 & 2,5 & 260 & [35] \\
\hline Brushite & 61 & 0,9 & 6 & 150 & [36] \\
\hline Monetite & 61 & 0,2 & 2,5 & 80 & [36] \\
\hline \multirow{4}{*}{$\beta$-ТCP } & 0 & 156 & 4000 & 26 & [88] \\
\hline & 45 & 6 & 50 & 120 & [36] \\
\hline & 60 & 2 & 18 & 111 & [35] \\
\hline & 80 & 1 & 4 & 250 & [36] \\
\hline \multirow{4}{*}{ Hydroxyapatite } & 1.6 & 137 & 9000 & 15 & [20] \\
\hline & 16 & 81 & 3800 & 21 & \\
\hline & 34 & 36,5 & 1000 & 37 & \\
\hline & 53.5 & 20 & 800 & 25 & \\
\hline \multirow{4}{*}{$\begin{array}{c}\text { La0.6Sr0.4Co0.2Fe } 0.803 \\
\text { Perovskite }\end{array}$} & 5 & 174 & 7000 & 25 & [21] \\
\hline & 29 & 80 & 2100 & 38 & \\
\hline & 36 & 44,5 & 900 & 49 & \\
\hline & 45 & 34 & 750 & 45 & \\
\hline \multirow{5}{*}{ Porous alumina } & 2.5 & 270 & 8000 & 34 & \multirow{3}{*}{ [54] } \\
\hline & 7 & 184 & 5000 & 37 & \\
\hline & 18 & 110 & 3800 & 29 & \\
\hline & 67 & 6 & 150 & 40 & \multirow{2}{*}[25]{} \\
\hline & 73 & 3 & 70 & 43 & \\
\hline
\end{tabular}

Table 2: Identified parameters for the constitutive behavior law of multiphasic CaP cements. Eo\&p is the experimental modulus determined by the Oliver and Pharr method, $E, \alpha, \beta$ and $k$ are the identified Young's modulus, friction angle, dilatancy angle at cohesion, respectively.

\begin{tabular}{|c|c|c|c|}
\hline $\begin{array}{c}\text { Immersion } \\
\text { duration in PBS }\end{array}$ & $\mathbf{0}$ day & $\mathbf{1}$ day & $\mathbf{5 6}$ days \\
\hline EO\&P (MPa) & 629 & 430 & 1172 \\
\hline $\mathbf{E}(\mathbf{M P a})$ & 650 & 546 & 856 \\
\hline $\boldsymbol{\alpha}$ & 0.0094 & 0.008 & 0.013 \\
\hline $\boldsymbol{\beta}$ & 0.0002 & 0.0002 & 0.0002 \\
\hline $\mathbf{k}(\mathrm{MPa})$ & 0.43 & 0.28 & 0.57 \\
\hline
\end{tabular}


Table 3: Core and surface properties measured by instrumented indentation on porous DCPD and BTCP samples before immersion.

\begin{tabular}{|c|c|c|c|c|c|c|}
\hline & \multicolumn{2}{|c|}{ DCPD } & \multicolumn{2}{|c|}{ DCPA } & \multicolumn{2}{|c|}{$\beta$-ТCP } \\
\hline & $\begin{array}{c}\mathrm{H}(\mathrm{MPa}) \\
\text { avg }_{\text {std }}\end{array}$ & $\begin{array}{c}\text { E (MPa) } \\
\text { avg }_{\text {std }}\end{array}$ & $\begin{array}{c}\mathrm{H}(\mathrm{MPa}) \\
\text { avg }_{\text {std }}\end{array}$ & $\begin{array}{l}\text { E (MPa) } \\
\text { avg }_{\text {std }}\end{array}$ & $\begin{array}{l}\text { H (MPa) } \\
\text { avg }_{\text {std }}\end{array}$ & $\begin{array}{c}E(\mathrm{MPa}) \\
\text { avg }_{\text {std }}\end{array}$ \\
\hline surface & 9.23 .8 & 1101400 & $3.2_{0.5}$ & $267_{35}$ & $5.0_{0.5}$ & $788_{139}$ \\
\hline core & $6.1_{1.0}$ & 882113 & $1.9_{0.2}$ & $168_{25}$ & $3.8_{0.4}$ & $986_{44}$ \\
\hline
\end{tabular}

Table 4: Average values and standard deviations of hardness and Young's modulus of DCPD samples after different immersion durations in TRIS solution with daily refresh. Values for $H$ and $E$ were compared with an unpaired statistical t-test. Differences between core and surface were shown to be statistically significant $(p<0.01)$.

\begin{tabular}{|c|l|l|l|l|}
\hline \multirow{2}{*}{$\begin{array}{c}\text { Immersion } \\
\text { duration }\end{array}$} & \multicolumn{2}{|c|}{$\begin{array}{c}\text { H (MPa) } \\
\text { avg }\end{array}$} & \multicolumn{2}{c|}{$\begin{array}{c}\text { E (MPa) } \\
\text { avg }\end{array}$} \\
\cline { 2 - 5 } & SURFACE & \multicolumn{1}{|c|}{ CORE } & SURFACE & \multicolumn{1}{c|}{ CORE } \\
\hline 0 & $9.2_{3.8}$ & $6.1_{1.0}$ & $1_{101_{399}}$ & $882_{213}$ \\
\hline 1 day & $9.2_{1.2}$ & $6.7_{0.4}$ & $1_{236}$ & $8_{236}$ \\
\hline 4 days & $6.2_{0.7}$ & $6.7_{0.4}$ & $1_{1071}$ & $8_{73}$ \\
\hline 8 days & $3_{1.5}$ & $6.7_{0.3}$ & $579_{193}$ & $834_{125}$ \\
\hline 14 days & $8.0_{2.9}$ & $5.7_{0.3}$ & $578_{174}$ & $598_{369}$ \\
\hline
\end{tabular}

Table 5: Average values and standard deviations of hardness and Young's modulus of DCPA samples before ("O day") and after ("14 days") immersion in TRIS solution with daily refresh.

\begin{tabular}{|c|c|c|c|c|}
\hline Sample & $\begin{array}{c}\text { E surface } \\
\text { (MPa) } \\
\text { avg }_{\text {std }}\end{array}$ & $\begin{array}{l}\text { E core } \\
\text { (MPa) } \\
\text { avg }_{\text {std }}\end{array}$ & $\begin{array}{l}\text { H surface } \\
\text { (MPa) } \\
\text { avg }_{\text {std }} \\
\end{array}$ & $\begin{array}{l}\text { H core } \\
\text { (MPa) } \\
\text { avg }_{\text {std }}\end{array}$ \\
\hline DCPA, 0 day & $267_{35}$ & $168_{25}$ & 3.20 .5 & $1.9_{0.2}$ \\
\hline DCPA, 14 days & 75750 & 22835 & $7.9_{1.0}$ & 2.30 .1 \\
\hline $\begin{array}{c}\text { Evolution } \\
0 \text { day/14 days }\end{array}$ & $+183 \%$ & $+35 \%$ & $+147 \%$ & $+21 \%$ \\
\hline
\end{tabular}


Table 6: Average values and standard deviations of hardness and Young's modulus of multiphasic CaP samples after different immersion durations in PBS solution with periodic refresh.

\begin{tabular}{|c|c|c|c|c|}
\hline \multirow{2}{*}{$\begin{array}{l}\text { Immersion } \\
\text { duration }\end{array}$} & \multicolumn{2}{|c|}{$\begin{array}{c}\mathrm{H}(\mathrm{MPa}) \\
\text { avg }_{\text {std }}\end{array}$} & \multicolumn{2}{|c|}{$\begin{array}{l}\mathrm{E}(\mathrm{MPa}) \\
\text { avg }_{\text {std }}\end{array}$} \\
\hline & SURFACE & CORE & SURFACE & CORE \\
\hline 0 & $2.86_{0.24}$ & $2.04_{0.1}$ & $629_{55}$ & $440_{10}$ \\
\hline 30 minutes & $2.17_{0.37}$ & $1.98_{0.14}$ & $465_{35}$ & $431_{55}$ \\
\hline 1 day & $4.25_{1.1}$ & $2.01_{0.1}$ & $649_{83}$ & $445_{23}$ \\
\hline 4 days & $5.5_{1.7}$ & $\begin{array}{c}\text { Not } \\
\text { tested }\end{array}$ & $1024_{190}$ & $\begin{array}{c}\text { Not } \\
\text { tested }\end{array}$ \\
\hline 8 days & $6.22_{1.3}$ & $\begin{array}{c}\text { Not } \\
\text { tested }\end{array}$ & $978_{179}$ & $\begin{array}{c}\text { Not } \\
\text { tested }\end{array}$ \\
\hline 14 days & $5.1_{0.6}$ & $2.14_{0.14}$ & $1038_{246}$ & $536_{10}$ \\
\hline 28 days & $6.25_{1.7}$ & $3.52_{0.19}$ & $1349_{105}$ & $941_{76}$ \\
\hline 56 days & $5.3_{0.9}$ & $4.25_{0.24}$ & $1375_{156}$ & $1172_{40}$ \\
\hline
\end{tabular}

Table 7: Average values and standard deviations of hardness and Young's modulus before ("O day") and after different immersion durations of $\beta$-TCP samples in TRIS solution without refresh.

\begin{tabular}{|c|l|l|l|l|}
\hline \multirow{2}{*}{$\begin{array}{c}\text { Immersion } \\
\text { duration }\end{array}$} & \multicolumn{2}{|c|}{$\begin{array}{c}\text { H (MPa) } \\
\text { avg }\end{array}$} & \multicolumn{2}{c|}{$\begin{array}{c}\text { E (MPa) } \\
\text { avg }\end{array}$} \\
\cline { 2 - 5 } & SURFACE & \multicolumn{1}{|c|}{ CORE } & SURFACE & \multicolumn{1}{c|}{ CORE } \\
\hline 0 & $5.0_{0.5}$ & $3.8_{0.4}$ & $788_{199}$ & $9_{44}$ \\
\hline 1 week & $2.1_{1.3}$ & $3.9_{0.3}$ & $663_{122}$ & $916_{16}$ \\
\hline 4 weeks & $1.8_{0.2}$ & $3.9_{0.3}$ & $4_{59}$ & $919_{20}$ \\
\hline 8 weeks & $3.5_{1.4}$ & $3.7_{1.5}$ & $507_{199}$ & $927_{297}$ \\
\hline
\end{tabular}


a)

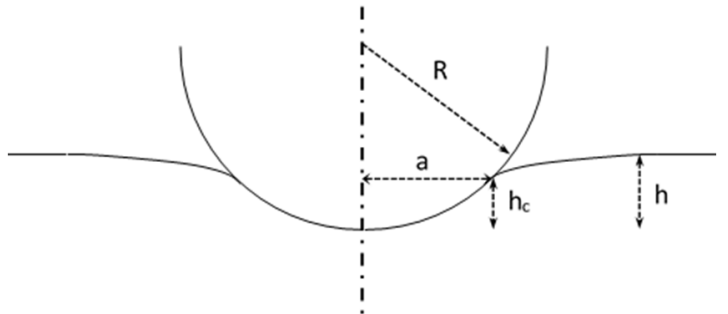

b)

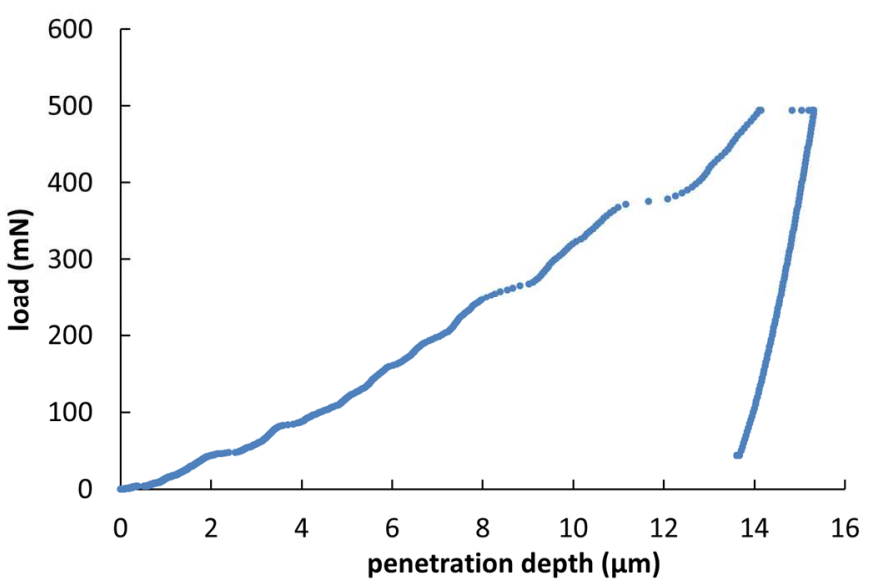

d)

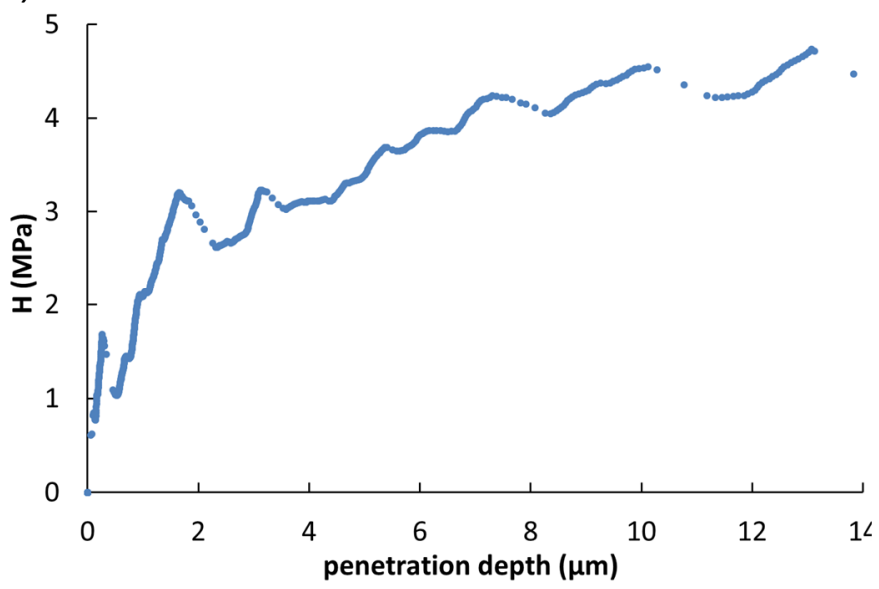

$2 \mathrm{~N}$

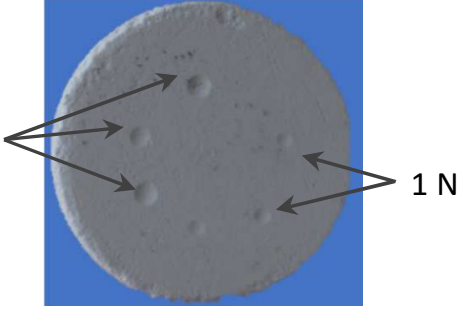

c)

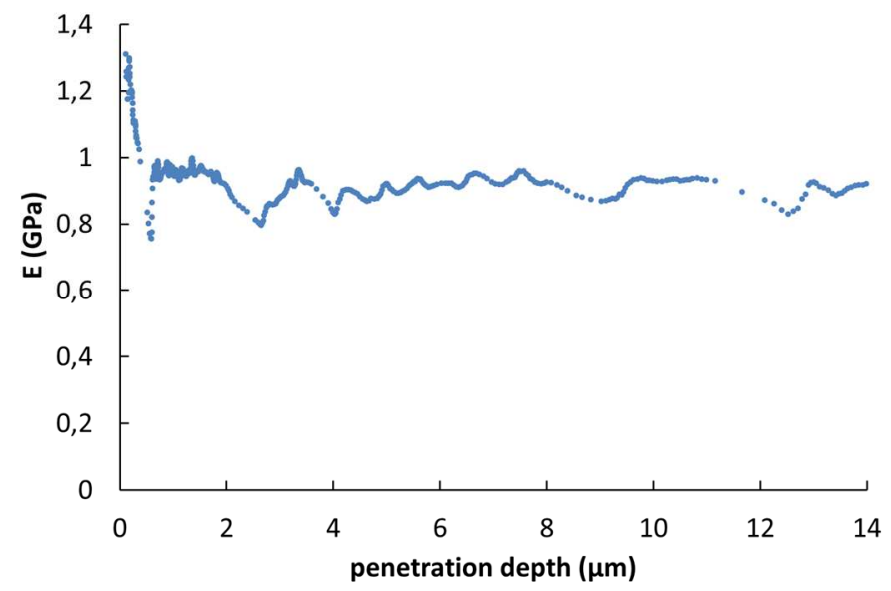

e)

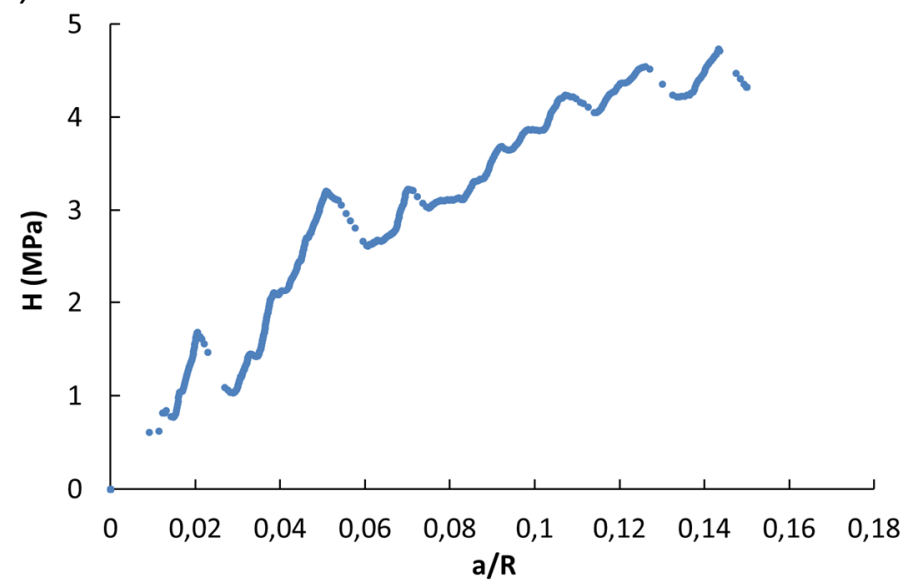

Figure 1: a) Schematic description of the spherical indentation test and picture of an indented multiphasic CaP sample with two different indentation loads: $1 \mathrm{~N}$ and $2 \mathrm{~N}$ (diameter of the sample $12 \mathrm{~mm}$, sphere diameter $3 \mathrm{~mm}$ ).

Example of a $\beta-T C P$ sample: $b$ ) typical load displacement curve, c) Young's modulus versus penetration depth, $d$ ) hardness versus penetration depth, e) hardness versus $a / R$. 


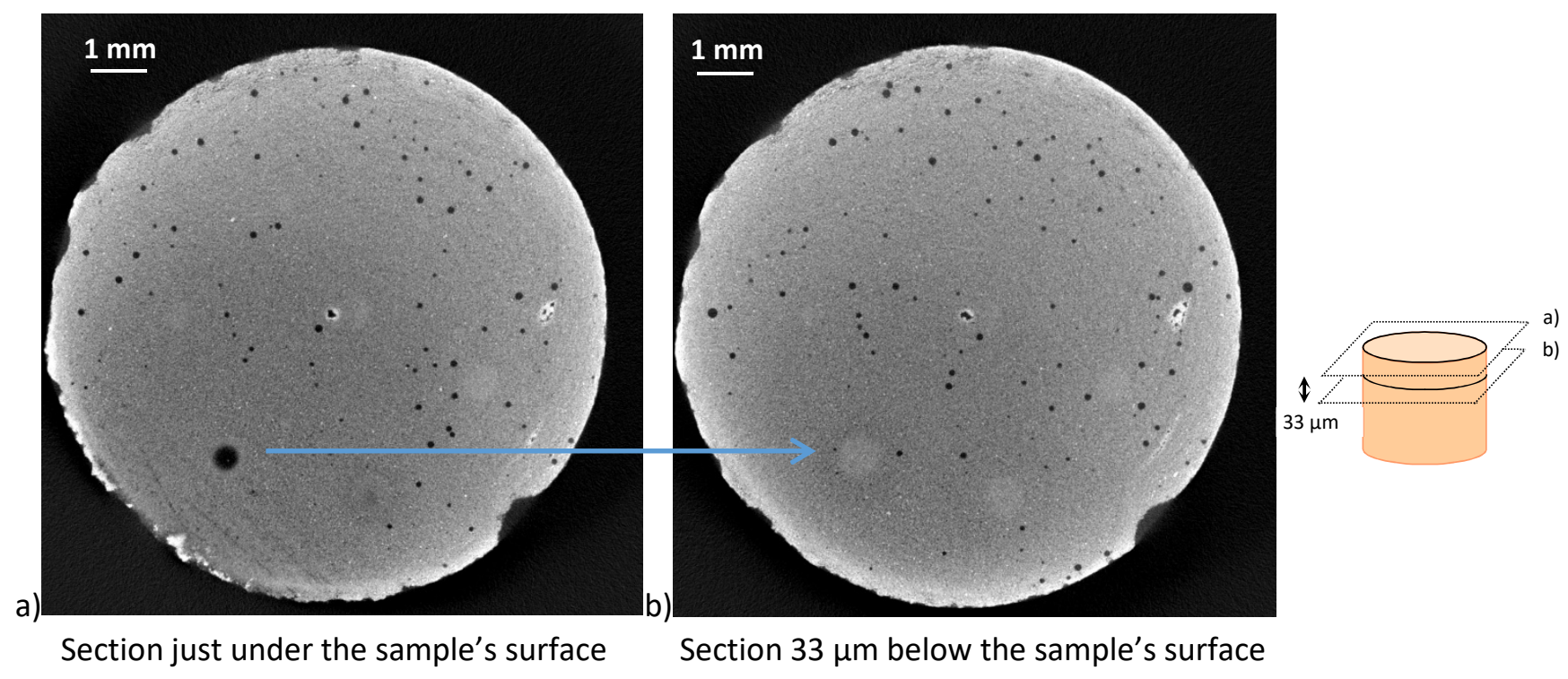

c)

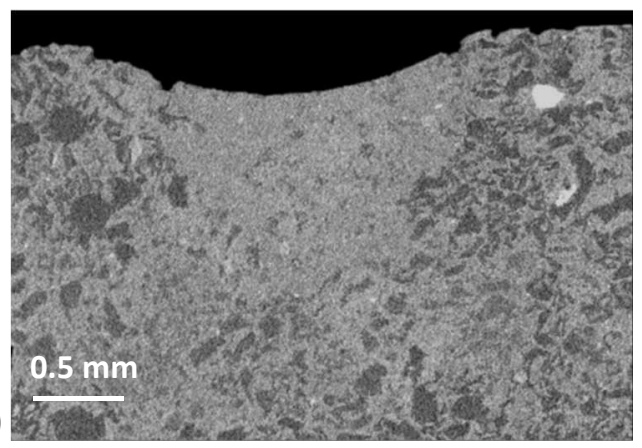

Figure 2: Slices of an X-ray Tomography volume of an indented sample of multiphasic CaP (diameter $12 \mathrm{~mm}$ ): a) slice just below the indented surface, b) slice at $33 \mu \mathrm{m}$ below the indented surface. Indents (2 $\mathrm{N}$ with a $3 \mathrm{~mm}$ diameter sphere) are shown by brighter disks due to densification of the materials below the indenter. On the bottom left part of the sample, a residual indent is visible as a dark disk in a) (slice through the residual imprint) and as a brighter disk in b) (slice through the densified zone below the indent) - see arrow, c) slice perpendicular to the indented surface of a gypsum sample tested at $20 \mathrm{~N}$ with a sphere diameter of $3 \mathrm{~mm}$, passing through an indent and showing extensive densification. The high indentation load was specifically chosen to clearly visualize the densification. 
a)

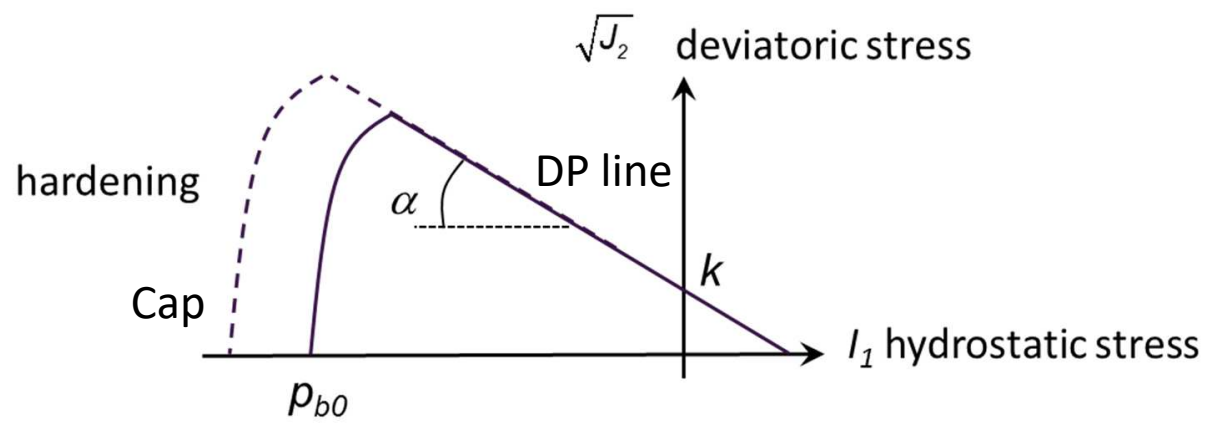

b)
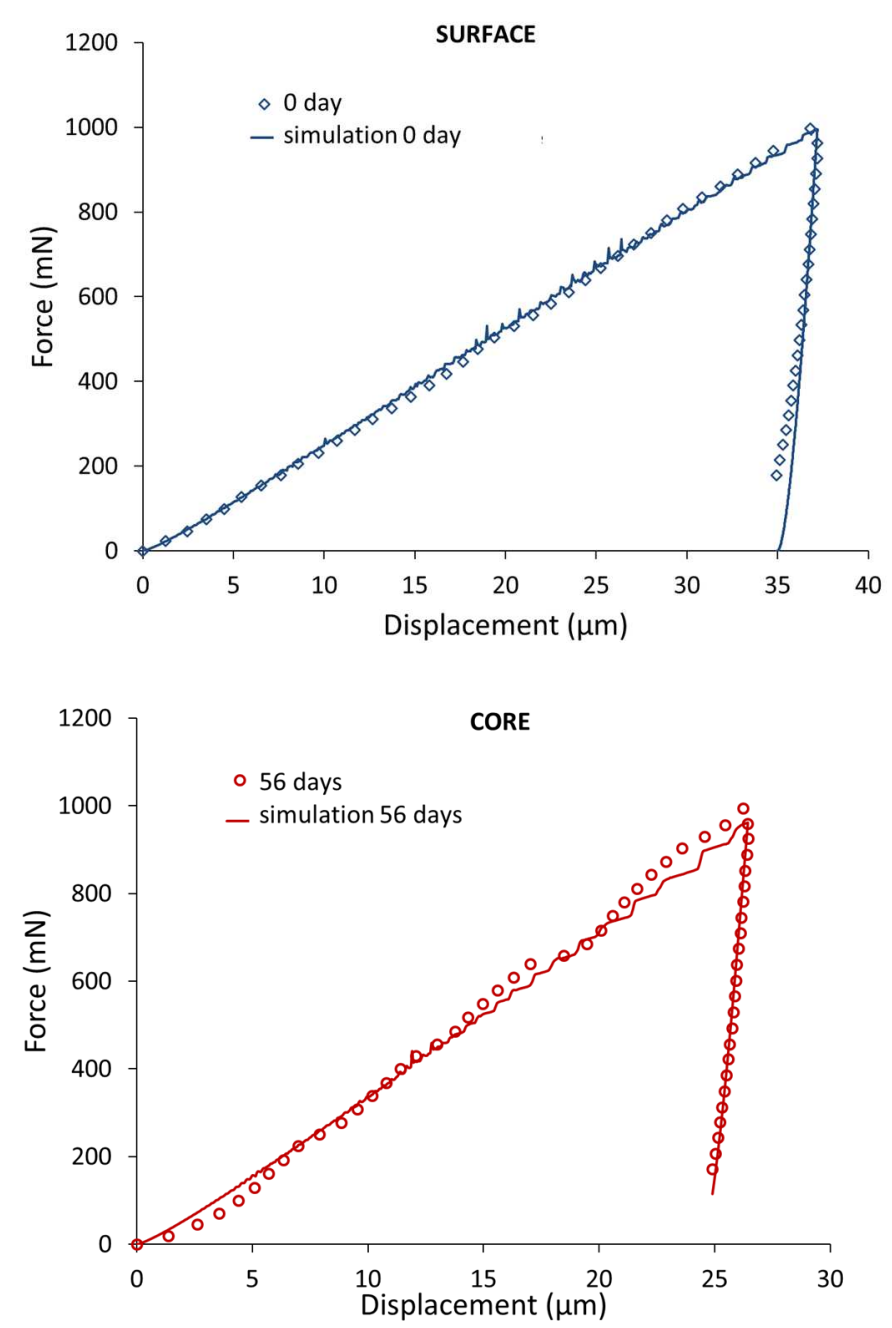

Figure 3: a) Schematic representation of Drücker-Prager criterion with cap in the hydrostatic stress deviatoric stress plane. $k$ stands for cohesion, $\alpha$ friction coefficient, $P_{b o}$ is pressure at the beginning of densification. A dotted line shows the evolution of the cap line with densification of the material. $b$ ) Comparison of the experimental and modeled load-displacement curve of an indentation test in a multiphasic CaP cement before immersion (surface) and after 56 days in PBS (core). 

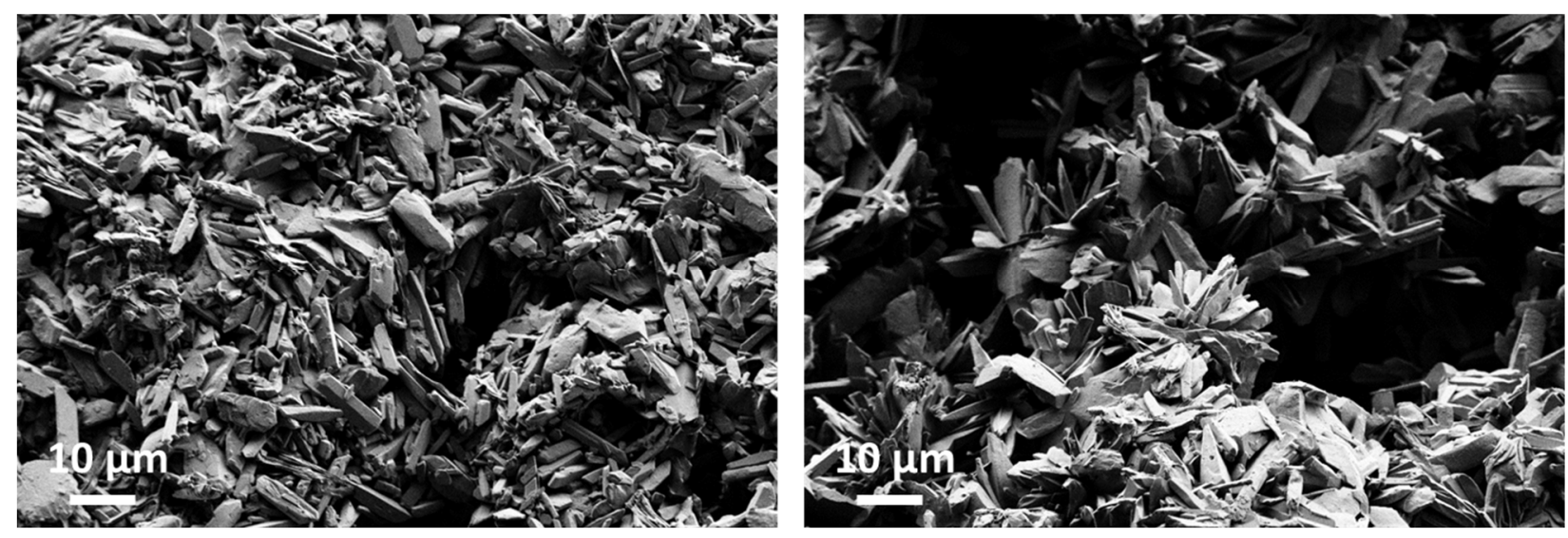

Figure 4: SEM images of the surface (left) and of the core (right) of a DCPD sample before immersion. Oriented DCPD crystals are noted at the surface, whereas a more random-like crystallization is noted in the core. 
a)
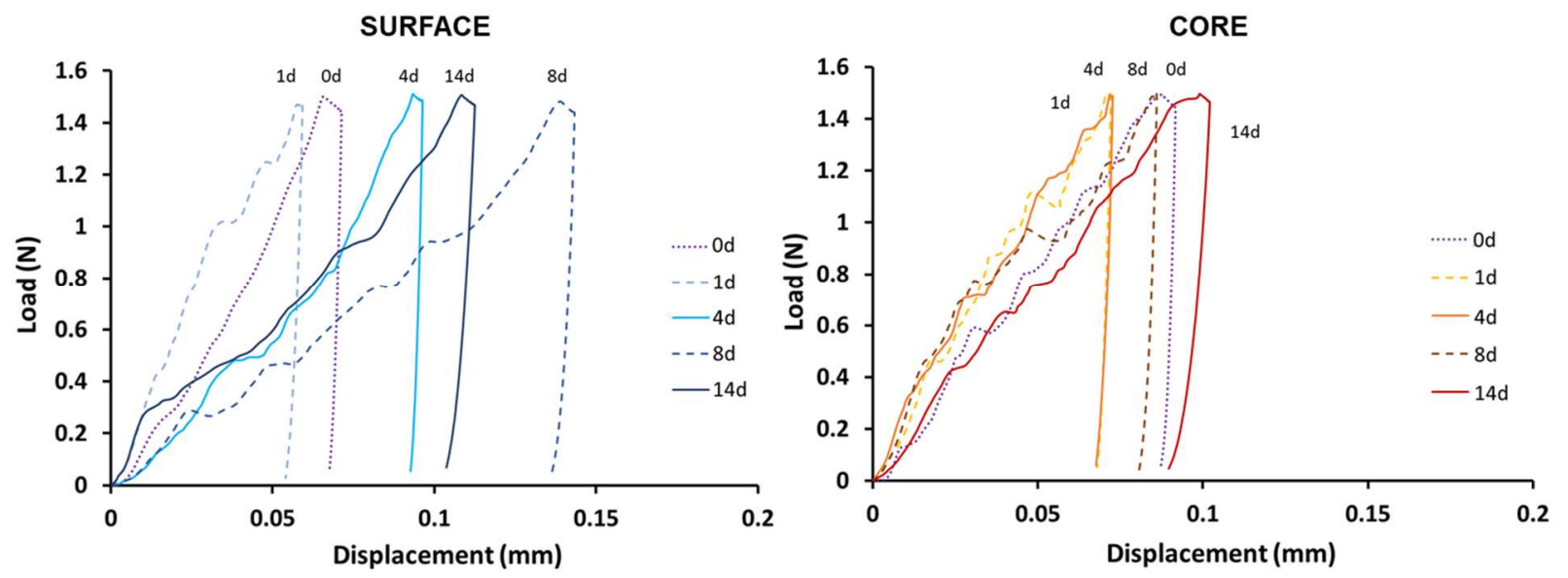

b)

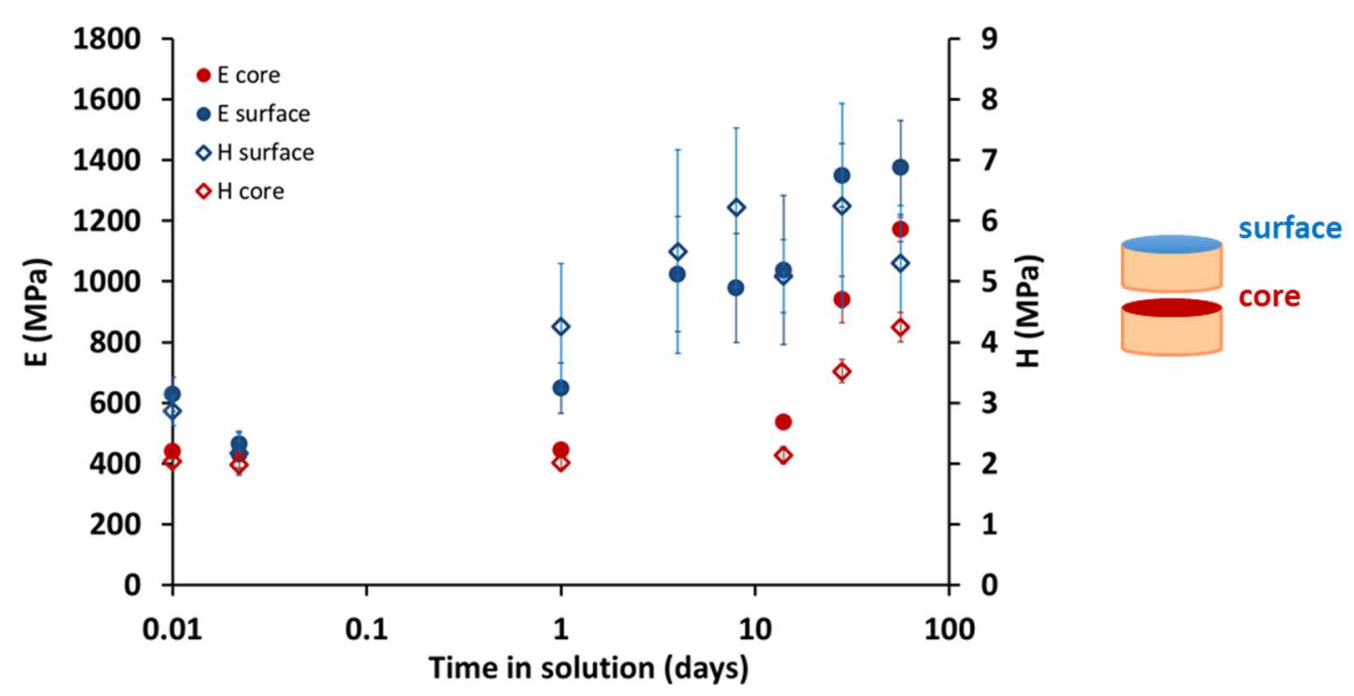

Figure 5: a) Instrumented indentation curves on DCPD samples immersed in TRIS solution with daily refresh up to 14 days. Left figure presents test at the surface of samples and right figure at the core of the samples, once cut in two halves.

b) Evolution of Young's modulus and hardness versus the immersion duration of multiphasic CaP samples immersed in refreshed PBS: blue marks for measurements at the surface, red marks for measurements at the core. 
a)
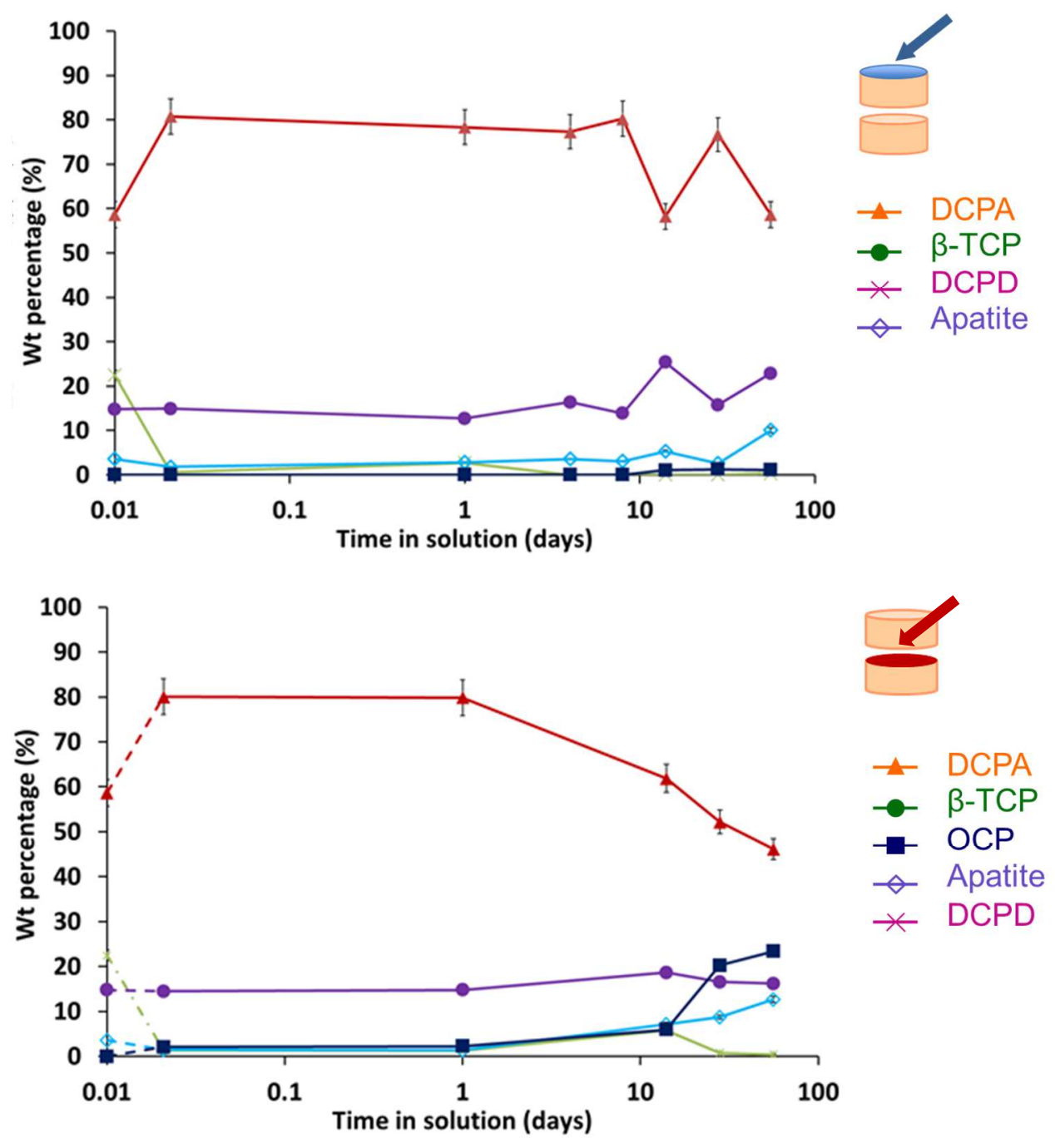

b)

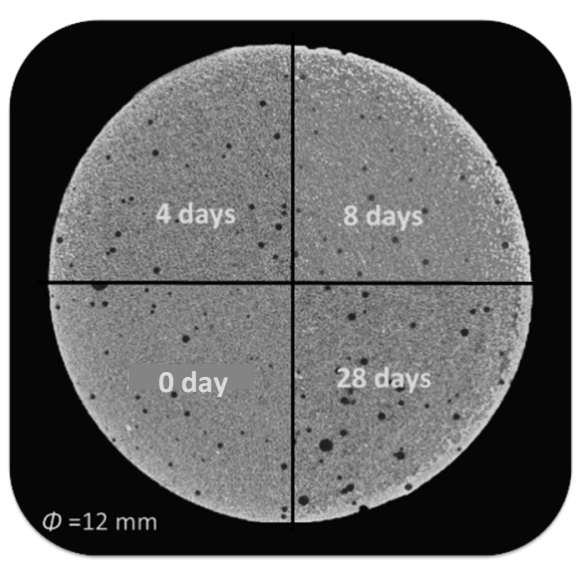

Figure 6: Multiphasic CaP samples during immersion in PBS solution with refresh

a) Evolution of the phase composition as measured by XRD and Rietveld analysis. Top figure:

measurement at the sample surface (approx. penetration depth of X-rays $100 \mu \mathrm{m}$ ), Bottom figure: measurement at the core after cutting the samples into two halves.

b) Sections of X-ray tomography scans in a reference state (bottom left quarter) and after 4 days (upper left), 8 days (upper right) and 28 days (bottom right) in PBS. 


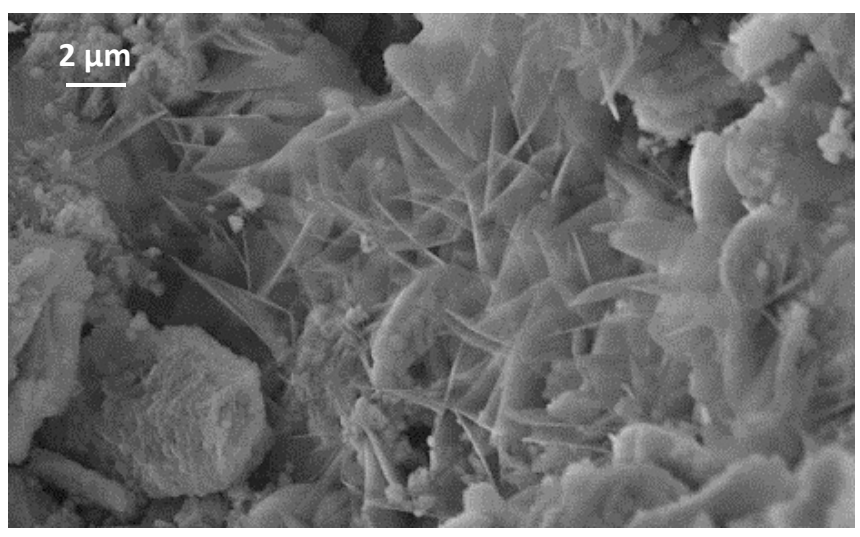

Figure 7: SEM images of precipitated OCP in a multiphasic CaP sample. 
a)
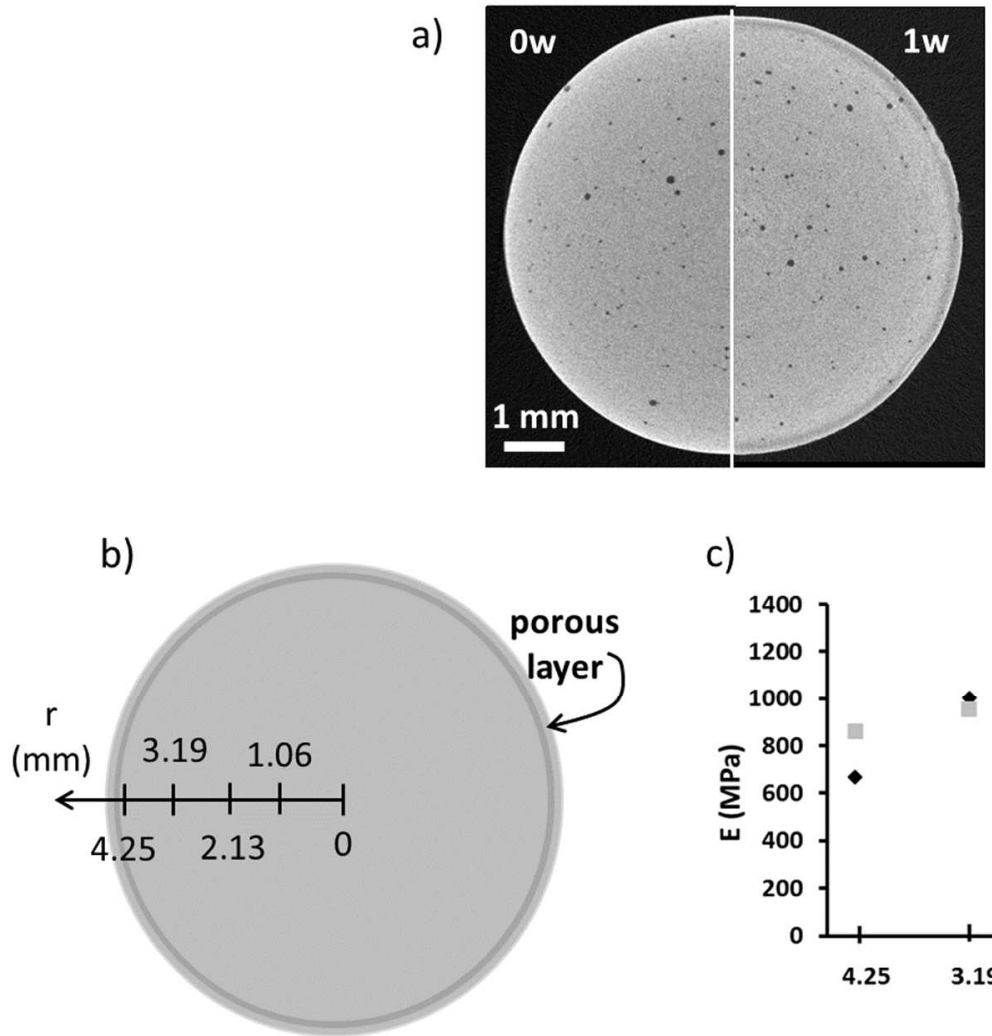

c)

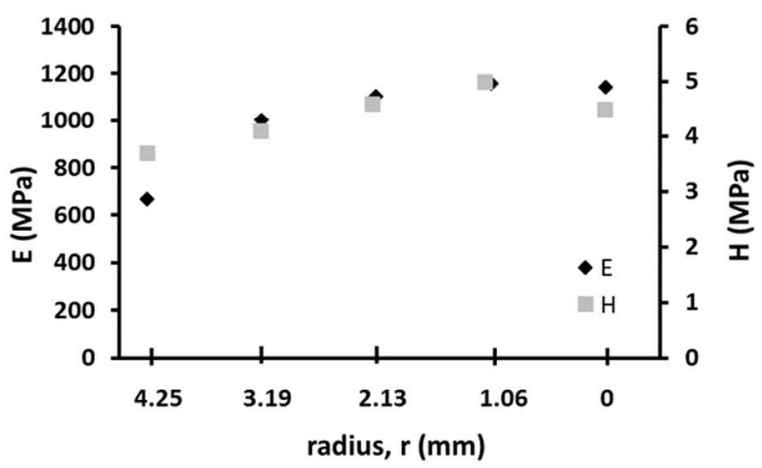

Figure 8: a) Section of a X-ray tomography volume of a resorbed $\beta$-TCP sample before (Ow) and after (1w) immersion of 1 week in TRIS solution with daily refresh. Sample diameter was $9.5 \mathrm{~mm}$.

b) Scheme of the section of a resorbed $\beta$-TCP sample, after 1 week (1w) of immersion in TRIS solution with daily refresh. The darker ring close to the surface represents the porous layer observed by X-ray tomography. Points where indentations were performed are labeled with their distance to the center point (radius r). c) Values of hardness (grey) and Young's modulus (black) vs. distance to the center of the sample. 
a)

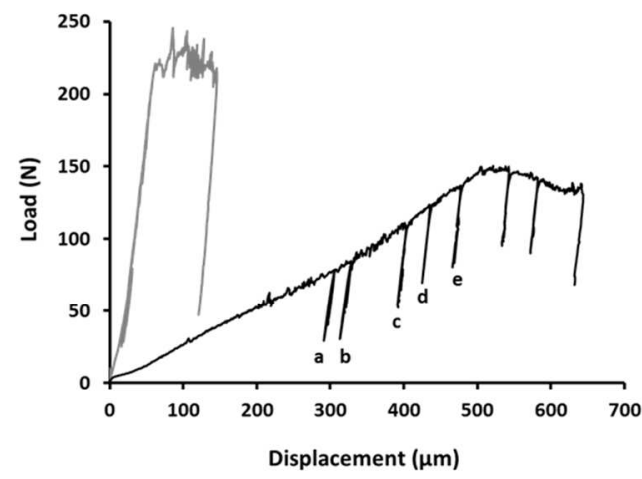

b)

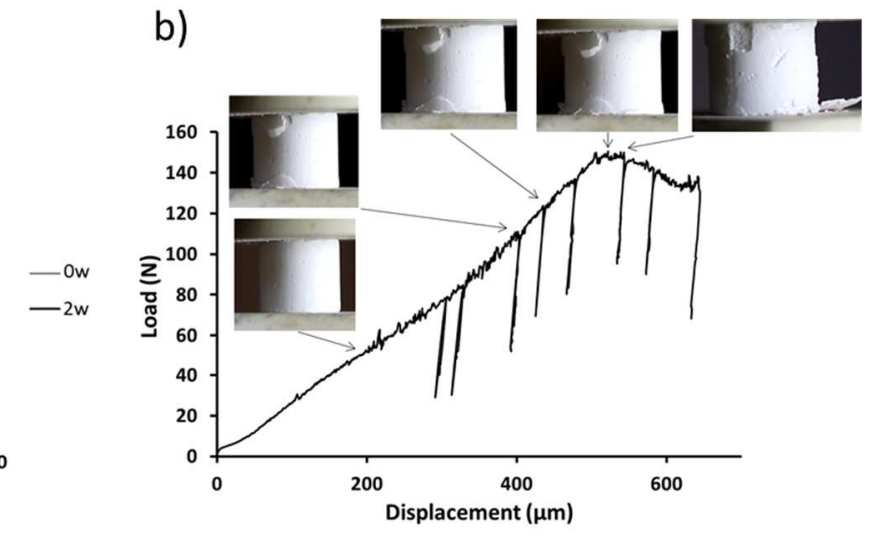

c)

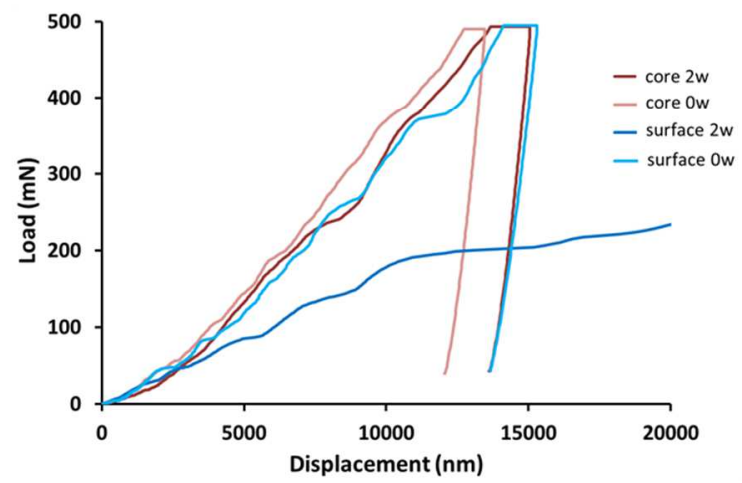

Figure 9: a) Load-displacement curve in uniaxial compression performed on a $\beta$-TCP sample before immersion (to - grey) and after 2 weeks in TRIS solution with daily refresh ( $2 w$-black). b) Loadingunloading cycles were performed for the sample tested after immersion. Pictures of a sample during the test are also shown in the image on the right.

c) Load-displacement curves in instrumented indentation on $\beta$-TCP samples before immersion (tO) and after 2 weeks in TRIS solution with daily refresh $(2 w)$ both at the surface and at the core. 


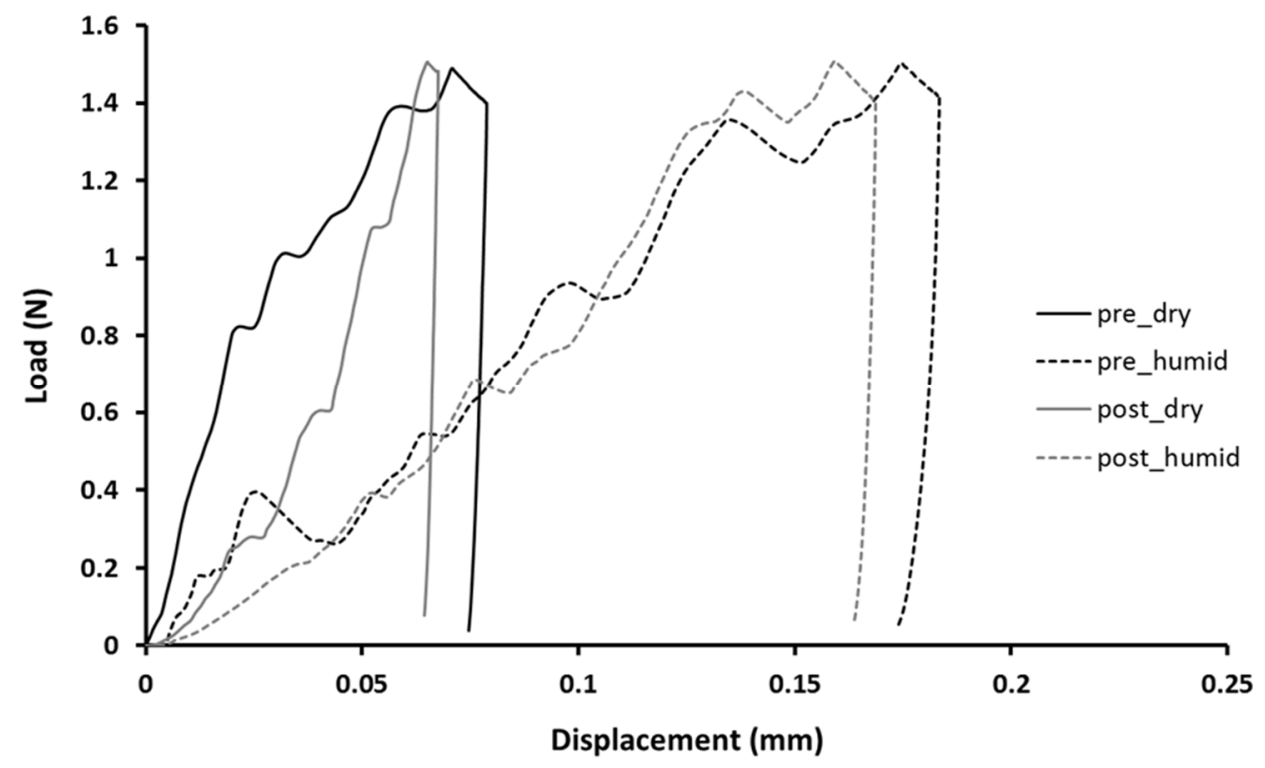

Figure 10: Indentation curves of DCPD samples obtained in dry (in black) and humid (in grey) conditions before (solid lines) and after (dotted lines) immersion for 14 days in TRIS solution without refresh. 


\section{References}

[1] S. Schaefer, R. Detsch, F. Uhl, U. Deisinger, and G. Ziegler, "How Degradation of Calcium Phosphate Bone Substitute Materials is influenced by Phase Composition and Porosity," Adv. Eng. Mater., vol. 13, no. 4, pp. 342-350, Apr. 2011.

[2] F. Peters and D. Reif, "Functional Materials for Bone Regeneration from Beta-Tricalcium Phosphate," Materwiss. Werksttech., vol. 35, no. 4, pp. 203-207, Apr. 2004.

[3] K. De Groot, "Effect of Porosity and Physicochemical Properties on the Stability, Resorption, and Strength of Calcium Phosphate Ceramics," Ann. N. Y. Acad. Sci., vol. 523, no. 1 Bioceramics, pp. 227-233, Jun. 1988.

[4] M. Bohner, Bioresorbable Ceramics. Boston: Woodhead Publishing in Materials, 2008.

[5] R. Detsch and A. R. Boccaccini, "The role of osteoclasts in bone tissue engineering," J. Tissue Eng. Regen. Med., vol. 9, no. 10, pp. 1133-1149, Oct. 2015.

[6] L. Gremillard et al., Degradation of bioceramics, vol. 9781461439. 2012.

[7] M. Gallo, S. Tadier, S. Meille, and J. Chevalier, "Resorption of calcium phosphate materials: Considerations on the in vitro evaluation," J. Eur. Ceram. Soc., vol. 38, no. 3, pp. 899-914, 2018.

[8] L. M. Grover, J. C. Knowles, G. J. P. Fleming, and J. E. Barralet, "In vitro ageing of brushite calcium phosphate cement," Biomaterials, vol. 24, no. 23, pp. 4133-4141, Oct. 2003.

[9] M. Gallo, S. Tadier, S. Meille, L. Gremillard, and J. Chevalier, "The in vitro evolution of resorbable brushite cements: A physico-chemical, micro-structural and mechanical study," Acta Biomater., vol. 53, pp. 515-525, 2017.

[10] I. Ajaxon, C. Öhman, and C. Persson, "Long-Term In Vitro Degradation of a High-Strength Brushite Cement in Water, PBS, and Serum Solution," Biomed Res. Int., vol. 2015, pp. 1-17, Oct. 2015.

[11] A. Bannerman et al., "Visualising phase change in a brushite-based calcium phosphate ceramic," Sci. Rep., vol. 6, no. August 2015, p. 32671, 2016.

[12] W. C. Oliver and G. M. Pharr, "An improved technique for determining hardness and elastic modulus using load and displacement sensing indentation experiments," J. Mater. Res., vol. 7, no. 6 , pp. 1564-1583, 1992.

[13] W. C. Oliver and G. M. Pharr, "Measurement of hardness and elastic modulus by 
instrumented indentation: Advances in understanding and refinements to methodology," J. Mater. Res., vol. 19, no. 01, pp. 3-20, 2004.

[14] S. Bec, A. Tonck, J.-M. Georges, E. Georges, and J.-L. Loubet, "Improvements in the indentation method with a surface force apparatus," Philos. Mag. A, vol. 74, no. 5, pp. 10611072, Nov. 1996.

[15] D. B. Marshall et al., "The Compelling Case for Indentation as a Functional Exploratory and Characterization Tool," J. Am. Ceram. Soc., vol. 98, no. 9, pp. 2671-2680, 2015.

[16] L. H. He and M. V. Swain, "Understanding the mechanical behaviour of human enamel from its structural and compositional characteristics," J. Mech. Behav. Biomed. Mater., vol. 1, no. 1, pp. 18-29, 2008.

[17] Y. Bala et al., "Bone micromechanical properties are compromised during long-term alendronate therapy independently of mineralization," J. Bone Miner. Res., vol. 27, no. 4, 2012.

[18] Y. Bala et al., "Respective roles of organic and mineral components of human cortical bone matrix in micromechanical behavior: An instrumented indentation study," J. Mech. Behav. Biomed. Mater., vol. 4, no. 7, 2011.

[19] A. Diez-Perez et al., "Microindentation for in vivo measurement of bone tissue mechanical properties in humans," J. Bone Miner. Res., vol. 25, no. 8, pp. 1877-1885, 2010.

[20] L. H. He, O. C. Standard, T. T. Y. Huang, B. A. Latella, and M. V. Swain, "Mechanical behaviour of porous hydroxyapatite," Acta Biomater., vol. 4, no. 3, pp. 577-586, 2008.

[21] Z. Chen, X. Wang, A. Atkinson, and N. Brandon, "Spherical indentation of porous ceramics: Elasticity and hardness," J. Eur. Ceram. Soc., vol. 36, no. 6, pp. 1435-1445, 2016.

[22] A. Chanda, B. X. Huang, J. Malzbender, and R. W. Steinbrech, "Micro- and macro-indentation behaviour of Ba0.5Sr0.5Co0.8Fe0.2 O3-d perovskite," J. Eur. Ceram. Soc., vol. 31, no. 3, pp. 401-408, 2011.

[23] R. K. Chintapalli, E. Jimenez-Pique, F. G. Marro, H. Yan, M. Reece, and M. Anglada, "Spherical instrumented indentation of porous nanocrystalline zirconia," J. Eur. Ceram. Soc., vol. 32, no. 1, pp. 123-132, 2012.

[24] P. Clément, S. Meille, J. Chevalier, and C. Olagnon, "Mechanical characterization of highly porous inorganic solids materials by instrumented micro-indentation," Acta Mater., vol. 61, 
no. 18, 2013.

[25] D. Staub, S. Meille, V. Le Corre, L. Rouleau, and J. Chevalier, "Identification of a damage criterion of a highly porous alumina ceramic," Acta Mater., vol. 107, pp. 261-272, 2016.

[26] Q. Flamant et al., "Selective etching of injection molded zirconia-toughened alumina: Towards osseointegrated and antibacterial ceramic implants," Acta Biomater., vol. 46, pp. 308-22, 2016.

[27] S. Pathak and S. R. Kalidindi, "Spherical nanoindentation stress-strain curves," Mater. Sci. Eng. R Reports, vol. 91, pp. 1-36, 2015.

[28] J. S. Field and M. V. Swain, "A simple predictive model for spherical indentation," J. Mater. Res., vol. 8, no. 02, pp. 297-306, Feb. 1993.

[29] B. R. Lawn, "Indentation of Ceramics with Spheres: A Century after Hertz," J. Am. Ceram. Soc., vol. 81, no. 1998, pp. 1977-1994, 1998.

[30] Z. Chen, X. Wang, F. Giuliani, and A. Atkinson, "Surface quality improvement of porous thin films suitable for nanoindentation," Ceram. Int., vol. 40, no. 3, pp. 3913-3923, 2014.

[31] Z. Chen, X. Wang, F. Giuliani, and A. Atkinson, "Microstructural characteristics and elastic modulus of porous solids," Acta Mater., vol. 89, pp. 268-277, 2015.

[32] Y. T. Cheng and C. M. Cheng, "Scaling, dimensional analysis, and indentation measurements," Mater. Sci. Eng. R Reports, vol. 44, no. 4-5, pp. 91-150, 2004.

[33] C. Moussa, X. Hernot, O. Bartier, G. Delattre, and G. Mauvoisin, "Identification of the hardening law of materials with spherical indentation using the average representative strain for several penetration depths," Mater. Sci. Eng. A, vol. 606, pp. 409-416, 2014.

[34] G. Kermouche, E. Barthel, D. Vandembroucq, and P. Dubujet, "Mechanical modelling of indentation-induced densification in amorphous silica," Acta Mater., vol. 56, no. 13, pp. 3222$3228,2008$.

[35] P. Clement, "Détermination des propriétés mécaniques de céramiques poreuses par essais de microindentation instruméentée sphérique," INSA Lyon, 2013.

[36] M. Gallo, "In-vitro degradation of calcium phosphate bone substitutes : Coupled monitoring of the evolution of mechanical, microstructural and physico-chemical properties of DCPD and bTCP samples," INSA Lyon, 2015. 
[37] M. Bohner, "Calcium orthophosphates in medicine: from ceramics to calcium phosphate cements.," Injury, vol. 31 Suppl 4, pp. 37-47, Dec. 2000.

[38] P. Feldner, B. Merle, and M. Göken, "Determination of the strain-rate sensitivity of ultrafinegrained materials by spherical nanoindentation," J. Mater. Res., vol. 32, no. 8, pp. 1466-1473, 2017.

[39] W. C. Oliver and G. M. Pharr, "An improved technique for determining hardness and elastic modulus using load and displacement sensing indentation experiments," J. Mater. Res., vol. 7, no. 06, pp. 1564-1583, Jun. 1992.

[40] A. Bouterf, J. Adrien, E. Maire, X. Brajer, F. Hild, and S. Roux, "Identification of the crushing behavior of brittle foam: From indentation to oedometric tests," J. Mech. Phys. Solids, vol. 98, pp. 181-200, 2017.

[41] S. Basu, A. Moseson, and M. W. Barsoum, "On the determination of spherical nanoindentation stress-strain curves," J. Mater. Res., vol. 21, no. 10, pp. 2628-2637, 2006.

[42] A. J. Moseson, S. Basu, and M. W. Barsoum, "Determination of the effective zero point of contact for spherical nanoindentation," J. Mater. Res., vol. 23, no. 1, pp. 204-209, 2008.

[43] S. Meille and E. J. Garboczi, "Linear elastic properties of 2D and 3D models of porous materials made from elongated objects," Model. Simul. Mater. Sci. Eng., vol. 9, no. 5, pp. 371-390, 2001.

[44] J. Sanahuja, L. Dormieux, S. Meille, C. Hellmich, and A. Fritsch, "Micromechanical explanation of elasticity and strength of gypsum: From elongated anisotropic crystals to isotropic porous polycrystals," J. Eng. Mech., vol. 136, no. 2, 2010.

[45] J. Desrues, "Limitations du choix de l'angle de frottement pour le critère de plasticité de Drucker-Prager," Rev. Française Génie Civ., vol. 6, no. 5, pp. 853-862, 2002.

[46] S. Cariou, F. J. Ulm, and L. Dormieux, "Hardness-packing density scaling relations for cohesivefrictional porous materials," J. Mech. Phys. Solids, vol. 56, no. 3, pp. 924-952, 2008.

[47] F. Richard, "MIC2M Software," FEMTO Besançon, 1999. [Online]. Available: http://mic2m.univ.fcomte.fr.

[48] P. Clément, S. Meille, J. Chevalier, and C. Olagnon, "Mechanical characterization of highly porous inorganic solids materials by instrumented micro-indentation," Acta Mater., vol. 61, no. 18, pp. 6649-6660, 2013. 
[49] M. H. Leite and F. Ferland, "Determination of unconfined compressive strength and Young'smodulus of porous materials by indentation tests," Eng. Geol., vol. 59, no. 3-4, pp. 267-280, 2001.

[50] M. Miller, C. Bobko, M. Vandamme, and F. J. Ulm, "Surface roughness criteria for cement paste nanoindentation," Cem. Concr. Res., vol. 38, no. 4, pp. 467-476, 2008.

[51] A. Bouterf, S. Roux, F. Hild, J. Adrien, E. Maire, and S. Meille, "Digital volume correlation applied to X-ray tomography images from spherical indentation tests on lightweight gypsum," Strain, vol. 50, no. 5, 2014.

[52] M. C. Shaw and T. Sata, "The plastic behavior of cellular materials," Int. J. Mech. Sci., pp. 469478, 1966.

[53] Z. Chen, X. Wang, F. Giuliani, and A. Atkinson, "Fracture Toughness of Porous Material of LSCF in Bulk and Film Forms," J. Am. Ceram. Soc., vol. 98, no. 7, pp. 2183-2190, 2015.

[54] B. A. Latella, B. H. O 'connor, N. P. Padture, and B. R. Lawn, "Hertzian contact damage in porous alumina ceramics," J. Am. Ceram. Soc, vol. 80, no. 4, pp. 1027-31, 1997.

[55] J. She, J. F. Yang, Y. Beppu, and T. Ohji, "Hertzian contact damage in a highly porous silicon nitride ceramic," J. Eur. Ceram. Soc., vol. 23, no. 8, pp. 1193-1197, 2003.

[56] S. O. Kucheyev, A. V. Hamza, J. H. Satcher, and M. A. Worsley, "Depth-sensing indentation of low-density brittle nanoporous solids," Acta Mater., vol. 57, no. 12, pp. 3472-3480, 2009.

[57] Y. Toivola, A. Stein, and R. F. Cook, "Depth-sensing indentation response of ordered silica foam," J. Mater. Res., vol. 19, no. 01, pp. 260-271, 2004.

[58] R. W. Rice, Porosity of ceramics; properties and application. 1998.

[59] P. A. Vermeer and R. de Borst, "Non-Associated Plasticity for Soils, Concrete and Rock.," Heron, vol. 29, no. 3, pp. 1-64, 1984.

[60] H. F. Schweiger, "On the use of drucker-prager failure criteria for earth pressure problems," Comput. Geotech., vol. 16, no. 3, pp. 223-246, Jan. 1994.

[61] V. Magnenet, A. Giraud, and F. Homand, "Parameter sensitivity analysis for a Drücker-Prager model following from numerical simulations of indentation tests," Comput. Mater. Sci., vol. 44, no. 2, pp. 385-391, 2008.

[62] T. F. Wong and P. Baud, "Mechanical compaction of porous sandstone," Oil Gas Sci. Technol., 
vol. 54, no. 6, pp. 715-727, 1999.

[63] Sandler IS, DiMaggio F, and Baladi G, "GENERALIZED CAP MODEL FOR GEOLOGICAL MATERIALS," ASCE J Geotech Eng Div, vol. 102, no. 7, pp. 683-699, 1976.

[64] A. Gurson, "Continuum Theory of Ductile Rupture by Void Nucleation and Growth: Part IYield Criteria and Flow Rules for Porous Ductile Media," J. Eng. Mater. Technol, vol. 99, no. 1, pp. 2-15, 1977.

[65] Z. Chen, X. Wang, N. Brandon, and A. Atkinson, "Analysis of spherical indentation of porous ceramic films," J. Eur. Ceram. Soc., vol. 37, no. 3, pp. 1031-1038, 2016.

[66] K. Xin and J. C. Lambropoulos, "Spherical cavity expansion in densifying material," J. Appl. Phys., vol. 94, no. 10, pp. 6437-6441, 2003.

[67] G. E. Andreev, Brittle failure of rock materials : test results and constitutive models. A.A. Balkema, 1995.

[68] I. Ajaxon et al., "Elastic properties and strain-to-crack-initiation of calcium phosphate bone cements: Revelations of a high-resolution measurement technique," J. Mech. Behav. Biomed. Mater., vol. 74, no. March, pp. 428-437, 2017.

[69] J. Zhang, W. Liu, V. Schnitzler, F. Tancret, and J. M. Bouler, "Calcium phosphate cements for bone substitution: Chemistry, handling and mechanical properties," Acta Biomater., vol. 10, no. 3, pp. 1035-1049, 2014.

[70] P. Reynaud, M. Saâdaoui, S. Meille, and G. Fantozzi, "Water effect on internal friction of set plaster," Mater. Sci. Eng. A, vol. 442, no. 1-2 SPEC. ISS., 2006.

[71] M. Saâdaoui, S. Meille, P. Reynaud, and G. Fantozzi, "Internal friction study of the influence of humidity on set plaster," J. Eur. Ceram. Soc., vol. 25, no. 14, 2005.

[72] J. Chappuis, "A new model for a better understanding of the cohesion of hardened hydraulic materials," Colloids Surfaces A Physicochem. Eng. Asp., vol. 156, no. 1-3, pp. 223-241, 1999.

[73] E. M. Gartner, "Cohesion and expansion in polycrystalline solids formed by hydration reactions - The case of gypsum plasters," Cem. Concr. Res., vol. 39, no. 4, pp. 289-295, 2009.

[74] J. Luo, I. Ajaxon, M. P. Ginebra, H. Engqvist, and C. Persson, "Compressive, diametral tensile and biaxial flexural strength of cutting-edge calcium phosphate cements," J. Mech. Behav. Biomed. Mater., vol. 60, pp. 617-627, Jul. 2016. 
[75] C. Petit et al., "Fracture behavior of robocast HA/ $\beta$-TCP scaffolds studied by X-ray tomography and finite element modeling," J. Eur. Ceram. Soc., vol. 37, no. 4, 2017.

[76] D. Jauffrès, C. L. Martin, A. Lichtner, and R. K. Bordia, "Simulation of the elastic properties of porous ceramics with realistic microstructure," Model. Simul. Mater. Sci. Eng., vol. 20, no. 4, p. 045009, 2012.

[77] M. L. Oyen and R. F. Cook, "A practical guide for analysis of nanoindentation data," J. Mech. Behav. Biomed. Mater., vol. 2, no. 4, pp. 396-407, 2009.

[78] V. L. Ferguson, "Deformation partitioning provides insight into elastic, plastic, and viscous contributions to bone material behavior," J. Mech. Behav. Biomed. Mater., vol. 2, no. 4, pp. 364-374, 2009.

[79] L. J. Gibson, "Results From Demineralized Bone Creep Tests Suggest That Collagen Is Responsible for the Creep Behavior of Bone," J. Biomech. Eng., vol. 121, no. 2, p. 253, Apr. 1999.

[80] Z. Wu, T. A. Baker, T. C. Ovaert, and G. L. Niebur, "The effect of holding time on nanoindentation measurements of creep in bone," J. Biomech., vol. 44, no. 6, pp. 1066-1072, 2011.

[81] S. E. Olesiak, M. L. Oyen, and V. L. Ferguson, "Viscous-elastic-plastic behavior of bone using Berkovich nanoindentation," Mech. Time-Dependent Mater., vol. 14, no. 2, pp. 111-124, 2010.

[82] K. F. Leong, C. K. Chua, N. Sudarmadji, and W. Y. Yeong, "Engineering functionally graded tissue engineering scaffolds," J. Mech. Behav. Biomed. Mater., vol. 1, no. 2, pp. 140-152, 2008.

[83] F. J. O’Brien, "Biomaterials \& scaffolds for tissue engineering," Mater. Today, vol. 14, no. 3, pp. 88-95, 2011.

[84] M. Peroglio, L. Gremillard, J. Chevalier, L. Chazeau, C. Gauthier, and T. Hamaide, "Toughening of bio-ceramics scaffolds by polymer coating," J. Eur. Ceram. Soc., vol. 27, no. 7, pp. 26792685, 2007.

[85] M. Bohner et al., "Characterization and distribution of mechanically competent mineralized tissue in micropores of $\beta$-tricalcium phosphate bone substitutes," Mater. Today, vol. 20, no. 3, 2017. 
[86] L. Angker, M. V. Swain, and N. Kilpatrick, "Characterising the micro-mechanical behaviour of the carious dentine of primary teeth using nano-indentation," J. Biomech., vol. 38, no. 7, pp. 1535-1542, 2005.

[87] S. Meille, "Unpublished results." .

[88] A. Tricoteaux et al., "Influence of porosity on the mechanical properties of microporous $\beta$-TCP bioceramics by usual and instrumented Vickers microindentation," J. Eur. Ceram. Soc., vol. 31, no. 8, pp. 1361-1369, 2011. 